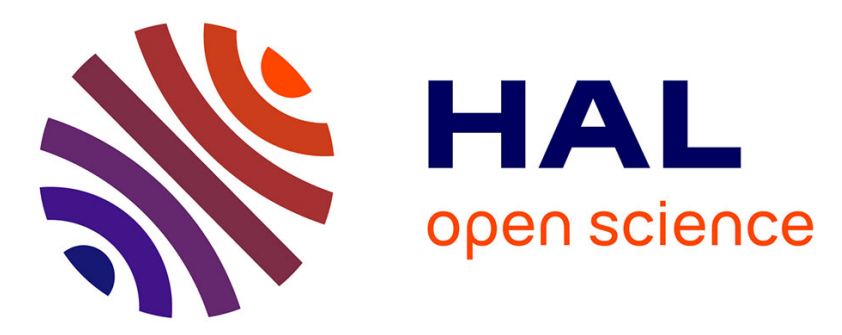

\title{
Crystal plasticity and phenomenological approaches for the simulation of deformation behavior in thin copper alloy sheets
}

Francis Adzima, Tudor Balan, Pierre-Yves Manach, Nicolas Bonnet, Laurent Tabourot

\section{To cite this version:}

Francis Adzima, Tudor Balan, Pierre-Yves Manach, Nicolas Bonnet, Laurent Tabourot. Crystal plasticity and phenomenological approaches for the simulation of deformation behavior in thin copper alloy sheets. International Journal of Plasticity, 2017, 94, pp.171-191. 10.1016/j.ijplas.2016.06.003 . hal-01556107

\section{HAL Id: hal-01556107 \\ https://hal.science/hal-01556107}

Submitted on 4 Jul 2017

HAL is a multi-disciplinary open access archive for the deposit and dissemination of scientific research documents, whether they are published or not. The documents may come from teaching and research institutions in France or abroad, or from public or private research centers.
L'archive ouverte pluridisciplinaire HAL, est destinée au dépôt et à la diffusion de documents scientifiques de niveau recherche, publiés ou non, émanant des établissements d'enseignement et de recherche français ou étrangers, des laboratoires publics ou privés. 


\title{
Crystal plasticity and phenomenological approaches for the simulation of deformation behavior in thin copper alloy sheets
}

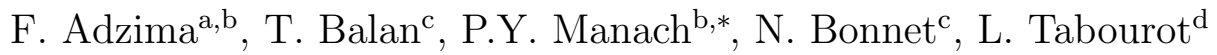 \\ ${ }^{a}$ Arts et Métiers ParisTech, LEM3, UMR CNRS 7239, 4 rue Augustin Fresnel, 57078 \\ Metz Cedex 3, France \\ ${ }^{b}$ Univ. Bretagne Sud, FRE CNRS 3744, IRDL, F-56100 Lorient, France \\ ${ }^{c}$ Arts et Métiers ParisTech, LCFC, EA 4495, 4 rue Augustin Fresnel, 57078 Metz Cedex \\ 3, France \\ ${ }^{d}$ Université de Savoie, SYMME, EA 4144, 74944 Annecy-le-Vieux, France
}

\begin{abstract}
In the expanding context of device miniaturization, forming processes of ultra thin sheet metals are gaining importance. Numerical simulation of these processes requires accurate material modeling. In this study, both the phenomenological modeling approach and the crystal plasticity finite element method (CPFEM) are considered. Theoretical definitions of both models, numerical implementation as well as their parameter identification procedures are outlined. Subsequently they are compared on a one to one basis, mainly with regards to their ability to predict mechanical responses for a variety of strain loading paths.
\end{abstract}

Keywords: A. Sheet metal forming B. Phenomenological modeling B. Crystal plasticity C. Finite elements

\footnotetext{
${ }^{*}$ Corresponding author

Email address: pierre-yves.manach@univ-ubs.fr (P.Y. Manach)
} 


\section{Introduction}

The current trend for product and device miniaturization has promoted micro-scale manufacturing processes. The demand for microparts has significantly increased in the automotive and electronics industries. Due to their suitability for mass production, sheet metal forming processes are widely used in the manufacturing industry and have been applied to very thin sheets. However, microforming raises a number of challenges related to the size of the parts targeted and the submillimetric thickness of the sheet metals (Geiger et al. (2001)). Finite element based simulations are nowadays common engineering tools. They allow to assess manufacturability of parts and to achieve subsequent time savings at the process design stage. Yet, the quality and predictiveness of these simulations rely on several factors, among which is the material behavior model. Currently, two distinct material modeling approaches can be considered for sheet metal forming. On one hand, the so-called phenomenological models are based on discrete macroscopic experimental observations and the assumption of material homogeneity. The constitutive laws consist of sets of relations with parameters which are adjusted to reproduce the experimental data available. Commercial finite element packages include several phenomenological laws for material modeling. Following the still extensively used von Mises model, quite a number of functions have been proposed to take into account anisotropy in the prediction of plastic yield. Extensive descriptions of most of them can be found in Banabic (2010). Beyond the yield point, the material behavior is described using so-called isotropic and/or kinematic hardening. Power (Swift type) and exponential (Voce type) laws are commonly used isotropic models while kinematic hardening modeling can involve expressions that are linear (Prager type), saturating (Armstrong and Frederick (1966)), a mix of these two types (Chaboche (1991)) or more conceptually complex (Yoshida and Uemori (2003) and Yoshida et al. (2015), Haddadi et al. (2006), Barlat et al. (2011)) depending on the material response during mechanical tests and the required modeling accuracy. On the other hand, the so-called microstructural models are based on the crystal plasticity theory which can be traced back to the works of Taylor and Elam (1923) and Schmid et al. (1934) who related plastic flow in single crystals to crystallographic planes slip. This class of model incorporate material heterogeneity, at microscopic level, in constitutive relations. We will restrict ourselves in this paper to the crystal plasticity finite element method (CPFEM) models which were initiated when Peirce 
et al. (1982) exploited the versatility of the finite element method to solve boundary value problems with crystal plasticity constitutive relations. Embedding the crystal plasticity theory into a finite element formulation enforces the equilibrium of the forces and compatibility of displacements between the grains of a polycrystal in a weak form through the principle of virtual work. The well known limitations (violation of equilibrium, assumptions on grains morphologies and interactions) of mean field models (Taylor (1938), Kröner (1961), Lebensohn and Tomé (1993), Van Houtte et al. (2005)) are overriden at the expense of a higher numerical cost. The unalterated growth of computing power over the last few decades has triggered an extensive use of CPFEM for various applications, in the research framework, Erieau and Rey (2004), Kim et al. (2012), Khadyko et al. (2015), Kim and Yoon (2015), Khan et al. (2015) as well as for industrial process simulations (Kalidindi and Anand (1992), Beaudoin et al. (1994), Grujicic and Batchu (2002), Li et al. (2008), Rousselier et al. (2009), Verma et al. (2013)). A thorough review of CPFEM features, applications and challenges can be found in Roters et al. (2010). Presently, although they provide a physically based simulation framework, CPFEM models are not available in commercial software. The phenomenological approach truly represents the standard constitutive modeling choice for industrial process simulations. Indeed, in addition to their computational efficiency, the latter approach has proven reliable and predicitive enough for most industrial applications.

Nevertheless, when it comes to processes involving very thin sheet metals with a few grains in the thickness, usually termed as ultra-thin sheet metals, phenomenological models often fail to render material behavior (Engel and Eckstein (2002), Geißdörfer et al. (2006), Peng et al. (2007)). As there are few grains, the individual response of each grain which is driven from its orientation, size and shape, strongly influences the behavior of the part being formed. During processing, these sheet metals present a strong heterogeneity of deformation. In such a context, the phenomenological approach which is based on the assumption of deformation homogeneity becomes questionnable. At the same time, CPFEM based process simulations become computationnally conceivable as the number of grains is lower (Wang et al. (2009)). The present study examines a case where the macroscopical lengthscale approaches the microstructural one but where scale separation is still workable. This paper aims at providing a one to one comparison of phenomenological and CPFEM based approaches in such a context. The ability of these approaches to predict the response of a copper alloy under differ- 


\begin{tabular}{ccccc}
\hline $\mathrm{Cu}$ & $\mathrm{Be}$ & $\mathrm{Co}$ & $\mathrm{Ni}$ & $\mathrm{Fe}$ \\
\hline 97 & $1.8-2$ & 0.3 & 0.15 & 0.15 \\
\hline
\end{tabular}

Table 1: Chemical composition in mass percent of $\mathrm{CuBe} 2$.

ent strain paths is investigated. First of all, the mechanical tests performed for the experimental characterisation of the considered material are briefly reported in Section 2. Hill (1948) and Bron and Besson (2004) anisotropic yield functions are considered in the phenomenological model and the developed parameter identification procedure is presented in Section 3. Then the adopted CPFEM framework, its embedment and numerical implementation as well as the parameter identification procedure are presented in Section 4. Comparisons of the two modeling approaches are performed in Section 5 and the main conclusions are presented in Section 6.

\section{Experimental characterization}

The studied material is the copper alloy $\mathrm{CuBe} 2$ whose chemical composition is given in Table 1. The cold rolled sheet is $0.1 \mathrm{~mm}$ thick and used in the micro-parts and connectors manufacturing industry. An industrial sheet metal grade is used for the experimental characterization, which is not annealed after cold rolling. The rolling direction of the sheet metal will be indicated RD, the transverse direction TD and the normal direction ND. Quantitative information on the microstructure was obtained from Electon BackScatter Diffraction (E.B.S.D.) scans. The microstructure was measured in the RD-TD and TD-ND sections. The device used in this study is a 7001 Field Electron Gun Scanning Electron Microscope from Jeol equiped with an Oxford EBSD CCD camera. EBSD data were post-treated with the software CHANNEL 5 from Oxford. The scanned areas were $320 \times 240 \mu \mathrm{m}^{2}$ large and the step size was set to $0.3 \mu \mathrm{m}$. No sensible microstructure gradient was observed and the grains were considered equiaxed. An EBSD map of the microstructure is shown in Fig. 1. The texture is marked and of Goss type. The experimentally measured average grain size was about $4 \mu \mathrm{m}$. Although the maximum grain size was about $50 \mu \mathrm{m}$, little dispersion was observed and the grain size was quite homogeneous leading to an average of 25 grains throughout the sheet thickness. These thin sheet metals provide a convenient framework for the upcoming models comparison as both phenomenological 

$\mathrm{GmbH})$.

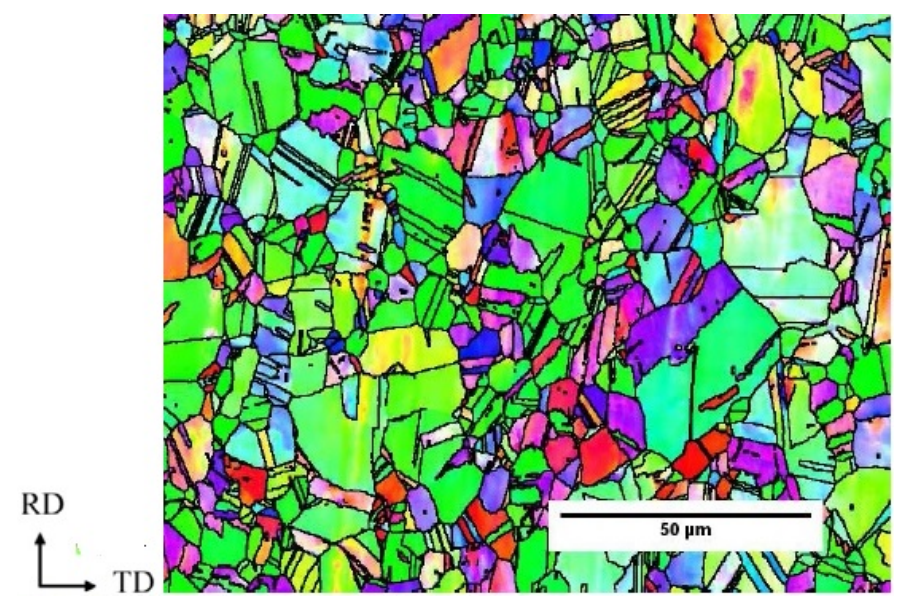

Figure 1: EBSD map of the industrial copper alloy $\mathrm{CuBe} 2$.

and microsctructural based models are still relevant. The influence of the reduction of the sheet thickness with respect to the grain size ( $\mathrm{T} / \mathrm{D}$ ratio) on models predictions will be assessed in future work.

In order to investigate the sheet behavior under different stress and strain paths, three types of mechanical tests were performed namely tensile tests, monotonic and Bauschinger shear tests and balanced biaxial tension. Strains were measured using Digital Image Correlation (DIC) system Aramis (GOM

\subsection{Tensile tests}

A sample geometry was prepared according to ISO 6892-1 standard, similarly to Pham et al. (2015). In order to evaluate material anisotropy, room temperature monotonous tensile tests were performed at $0^{\circ}, 45^{\circ}$ and $90^{\circ}$ from the RD. The tests were controlled by grip displacement and the strain rate was around $10^{-4} \mathrm{~s}^{-1}$. Each type of test was performed three times to ensure reproductibility of the results. Longitudinal $\epsilon_{x x}$ and transverse $\epsilon_{y y}$ logarithmic strains were recorded during the experiments. Plastic anisotropy coefficients $r_{\alpha}$ coefficients are used to quantify strain anisotropy. Strain anisotropy is quite pronounced especially in the sheet plane with a planar anisotropy coefficient $\Delta r=\left(r_{0}+r_{90}-2 r_{45}\right) / 2=0.28$ and a normal anisotropy coefficient $\bar{r}=\left(r_{0}+r_{90}+2 r_{45}\right) / 4=0.92$.

The influence of viscosity was studied by changing the strain rate during tensile tests in the RD. The strain rate was increased from $10^{-4} \mathrm{~s}^{-1}$ (up to 
$2 \%$ of deformation) to $10^{-3} \mathrm{~s}^{-1}$ (up to $4 \%$ of deformation) and $10^{-2} \mathrm{~s}^{-1}$ (up to $8 \%$ of deformation). Relaxation times of $60 \mathrm{~s}$ were imposed between the first two reloadings. Eventually, a relaxation time of $120 \mathrm{~s}$ was imposed and a strain rate of $10^{-4} \mathrm{~s}^{-1}$ was applied to the specimen.

\subsection{Shear tests}

Shear tests were performed with the device presented in Thuillier and Manach (2009). Rectangular samples of dimensions $30 \times 15 \mathrm{~mm}^{2}$ were used. Monotonic and reversed (Bauschinger) shear tests were performed in the RD at a strain rate of $\dot{\gamma}=8 \times 10^{-4} \mathrm{~s}^{-1}$. The shear strain $\gamma$ was obtained from the measured non diagonal component $\epsilon_{12}$ of the Green-Lagrange strain tensor as $\gamma=2 \epsilon_{12}$. The shear stress was calulated by $\sigma_{12}=F / S_{0}$ where $F$ is the load during the test and $S_{0}$ the initial gauge section.

\subsection{Balanced biaxial tensile test}

Material response at large strains and under a balanced biaxial strain state was investigated using a hydraulic bulge test (Zang et al. (2011)). A circular blank of a $60 \mathrm{~mm}$ gauge diameter was held on a circular die by a blank-holder fastened with screws. The blank was then deformed up to rupture by water pressure controlled with a sensor. The strain state on the sample surface was measured throughout the test. The curvature radius at the pole $R_{\text {pole }}$ was approximated by fitting a sphere over a selected area. A balanced biaxial stress state was assumed and the stress was then calculated using $\sigma=P R_{\text {pole }} / 2 e$ where $P$ is the hydraulic pressure and $e$ the current blank thickness.

The experimental stress-strain curves in the tensile test $\left(0^{\circ}\right.$ to the RD), balanced biaxial tensile test and simple shear test are shown in Fig. 2. The flow stress and work-hardening rate of the balanced biaxial tensile test and uniaxial tensile test are similar, while much larger strains are reached with the biaxial and shear tests. Detailed experimental results will be further shown in the subsequent sections, in comparison to numerical predictions.

\section{Phenomenological modeling and parameter identification}

\subsection{Constitutive model}

As sheet metal forming involves large strains and material rotation, the constitutive equations need to be written in a finite deformation framework. 


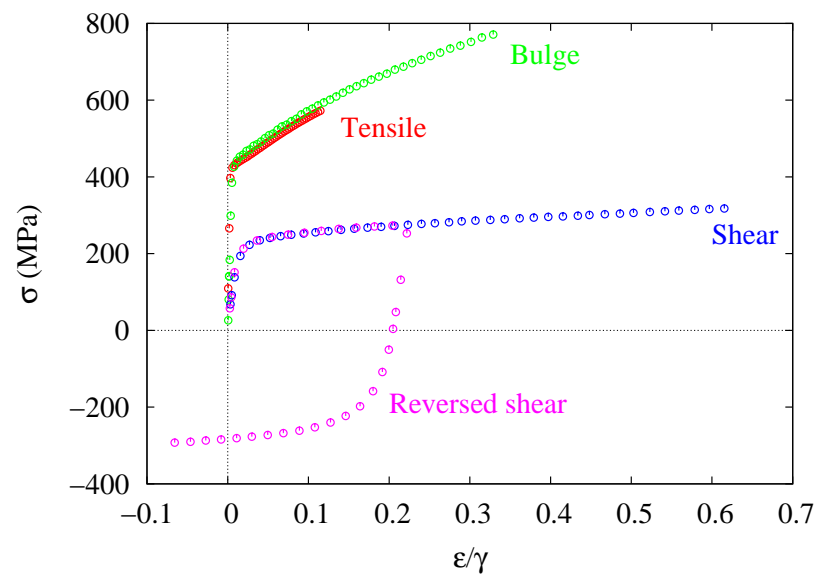

Figure 2: Stress-strain curves of the experimental strain paths investigated.

The following relations were implemented in the SiDoLo software (Cailletaud and Pilvin (1993)) which enables model development and inverse material parameter identification. To fulfill the material frame indifference requirement (principle of objectivity), the orthogonal rotating frame associated to the objective derivative of Jaumann (the so-called co-rotational frame) is considered as the main reference (Sidoroff (1982)).

\subsubsection{Elastic-viscoplasticity}

In its associated rotating frame, an objective derivative corresponds to a simple time derivative. Thus under the assumption of hypoelasticity, the constitutive elastic relation is written in an incremental form

$$
\dot{\boldsymbol{\sigma}}=\mathbf{C}: \mathbf{D}^{e}
$$

where $\boldsymbol{\sigma}$ is the rotation-compensated Cauchy stress tensor, $\mathbf{C}$ is the isotropic elastic modulus tensor which is expressed using the Young's modulus $E$ and Poisson's coefficient $\nu$ while $\mathbf{D}^{e}$ is the elastic part of the strain rate. The small-strain like splitting of the strain rate is assumed, leading to the following rate expression:

$$
\mathbf{D}^{e}=\mathbf{D}-\mathbf{D}^{p}
$$


where $\mathbf{D}$ is the total strain rate and $\mathbf{D}^{p}$ its viscoplastic part.

The material is assumed to behave elastically in a domain bounded by a yield surface defined by

$$
f(\boldsymbol{\sigma}, \mathbf{X}, R)=\bar{\sigma}(\boldsymbol{\sigma}, \mathbf{X})-R=0,
$$

where $\bar{\sigma}$ is the equivalent stress, $\mathbf{X}$ is the tensorial internal variable pointing to the centre of the yield surface which is used to model kinematic hardening, and $R$ is the isotropic hardening.

The viscoplastic strain rate tensor $\mathbf{D}^{p}$ accounting for plastic flow at yield is derived from a Norton-like viscoplastic potential $\Omega$ and the flow rule is then expressed by

$$
\mathbf{D}^{p}=\frac{\partial \Omega}{\partial \boldsymbol{\sigma}}
$$

The stress potential $\Omega$ is expressed as

$$
\Omega(f)=\frac{K_{v}}{n_{v}+1}\left(\frac{f_{+}}{K_{v}}\right)^{n_{v}+1}
$$

where $f_{+}$is the positive part of $f, K_{v}$ is a weighting coefficient of the viscous contribution and $n_{v}$ a strain-rate sensitivity coefficient.

Isotropic hardening is chosen as:

$$
R=\sigma_{\text {sat }}-\left(\sigma_{\text {sat }}-\sigma_{0}\right) \exp \left(-C_{R} p^{n_{r}}\right),
$$

where $n_{r}$ is a material parameter, $\sigma_{\text {sat }}$ is the saturation stress, $\sigma_{0}$ the initial yield stress, $C_{R}$ the saturation rate and $p$ the cumulated viscoplastic strain defined by

$$
p=\int_{0}^{t} \sqrt{\frac{2}{3} \mathbf{D}^{p}: \mathbf{D}^{p}} d t .
$$

The so-called back-stress tensor $\mathbf{X}$ is written as the sum of ArmstrongFrederick law terms with a Prager type term in order to achieve a good description both at larger strains and at the onset of plastic flow during reverse loading. The resulting expression is

$$
\mathbf{X}=\frac{2}{3}\left(\sum_{i=1}^{N} C_{X_{i}} \boldsymbol{\alpha}_{i}+H_{X} \mathbf{d}^{p}\right) ; \quad \mathbf{d}^{p}=\int_{0}^{t} \mathbf{D}^{p} d t
$$

with

$$
\dot{\boldsymbol{\alpha}}_{i}=\mathbf{D}^{p}-B_{X_{i}} \dot{p} \boldsymbol{\alpha}_{i}
$$


218

where $C_{X_{i}}$ is associated to the non-linear Armstrong-Frederick term, $B_{X_{i}}$ the parameter related to the recall term (memory effect) and $H_{X}$ the slope of the linear Prager term.

Material anisotropy is taken into account in the computation of the equivalent stress by mean of anisotropic yield functions. Hill's 1948 quadratic yield function and the Bron\&Besson yield function are considered in this work. Hill (1948) function is a widely used anisotropic yield function developed for materials exhibiting orthotropic symmetry just as rolled sheets.

The equivalent stress can be expressed as:

$$
\bar{\sigma}=\mathbf{T}^{\prime}: \mathbf{M}: \mathbf{T}^{\prime}
$$

where $\mathbf{T}=\boldsymbol{\sigma}-\mathbf{X}$ and $\mathbf{T}^{\prime}=$ deviator $(\mathbf{T})$.

$\mathrm{M}$ is the fourth order tensor inducing the anisotropy and writes in the material orthotropic frame :

$$
\mathbf{M}=\frac{1}{3}\left[\begin{array}{cccccc}
2 G+2 H-F & 0 & 0 & 0 & 0 & 0 \\
0 & 2 F+2 H-G & 0 & 0 & 0 & 0 \\
0 & 0 & 2 H+2 G-H & 0 & 0 & 0 \\
0 & 0 & 0 & N & 0 & 0 \\
0 & 0 & 0 & 0 & M & 0 \\
0 & 0 & 0 & 0 & 0 & L
\end{array}\right]
$$

where $F, G, H, L, M$ and $N$ are the anisotropy parameters.

Bron and Besson (2004) yield function is an extension of the Karafillis and Boyce (1993) criterion in which anisotropy is introduced by means of linear transformations. The equivalent stress is expressed as:

$$
\bar{\sigma}=\left(\sum_{k=1}^{2} \lambda_{k}\left(\psi_{k}\right)^{\frac{a}{b_{k}}}\right)^{\frac{1}{a}} ; \sum \lambda_{k}=1 .
$$

The functions $\psi_{k}$ are first order homogeneous, positive, convex with respect to their argument and defined by:

$$
\psi_{1}=\frac{1}{2}\left(\left|S_{2}^{1}-S_{3}^{1}\right|^{b_{1}}+\left|S_{3}^{1}-S_{1}^{1}\right|^{b_{1}}+\left|S_{1}^{1}-S_{2}^{1}\right|^{b_{1}}\right),
$$

$$
\text { and } \psi_{2}=\frac{3^{b_{2}}}{2^{b_{2}}+2}\left(\left|S_{1}^{2}\right|^{b_{2}}+\left|S_{2}^{2}\right|^{b_{2}}+\left|S_{3}^{2}\right|^{b_{2}}\right) \text {. }
$$


$S_{i=1,3}^{k}$ are the eigenvalues of the modified deviatoric stress tensor $\mathbf{s}^{\prime}{ }^{k}$. These tensors are obtained from linear transformations on the tensor $\mathbf{T}$ which are expressed as:

$$
\mathbf{s}^{\prime}{ }^{k}=\mathbf{L}^{k}: \mathbf{T},
$$

and where the anisotropy parameters are embedded in the symmetric fourth order tensors $\mathbf{L}^{k}$ :

$$
\mathbf{L}^{k}=\frac{1}{3}\left[\begin{array}{cccccc}
c_{2}^{k}+c_{3}^{k} & -c_{3}^{k} & -c_{2}^{k} & 0 & 0 & 0 \\
-c_{3}^{k} & c_{3}^{k}+c_{1}^{k} & -c_{1}^{k} & 0 & 0 & 0 \\
-c_{2}^{k} & -c_{1}^{k} & c_{1}^{k}+c_{2}^{k} & 0 & 0 & 0 \\
0 & 0 & 0 & 3 c_{4}^{k} & 0 & 0 \\
0 & 0 & 0 & 0 & 3 c_{5}^{k} & 0 \\
0 & 0 & 0 & 0 & 0 & 3 c_{6}^{k}
\end{array}\right]
$$

Thus through the two linear transformations, twelve parameters $c_{i=1,6}^{k=1,2}$ are provided to describe anisotropy. The parameters $\lambda=\lambda_{1}, a, b_{1}$ and $b_{2}$ affect the yield surface's shape.

\subsection{Parameter identification}

A number of material parameters could be determined independently by specific measurements. The remaining ones were determined by inverse identification. Young's modulus $E$ and Poisson's ratio $\nu$ were determined from sequential loading-unloadings in the elastic domain. The initial Young modulus was $120 \mathrm{MPa}$, then it decreased with plastic strain and rapidly reached a saturation value of $95 \mathrm{MPa}$. Consequently, this later value was used for the simulations throughout the current investigation.

The viscous contribution to material behavior is assessed by the increasing strain rate tensile tests and the viscous parameters of $\mathrm{Eq}(5), K_{v}$ and $n_{v}$, were identified based on these experiments. After identification of the isotropic hardening parameters, consistency of viscosity parameters obtained beforehand was assessed through the simulation of the increasing strain rate tensile test. The experimental test and its simulated counterpart are shown in Fig. 3. The viscosity effect is relatively small, at least under such homogeneous loading conditions. 


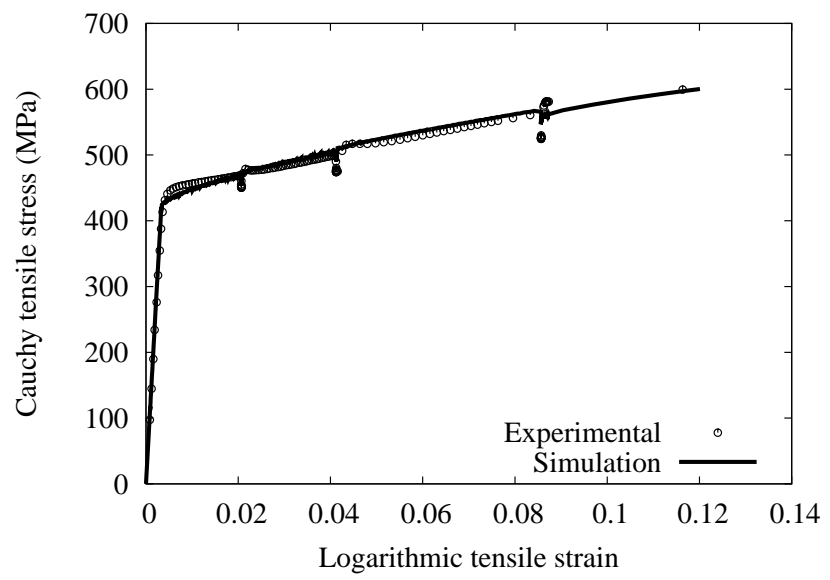

Figure 3: Experimental and predicted increasing strain rate uniaxial tensile test in the $\mathrm{RD}$.

\subsubsection{Inverse identification procedure}

A set of material parameters was sought to minimize the gap between the experimental tests and model predictions. Starting from an initial parameter set, an optimisation process was conducted with a gradient type algorithm in order to minimize an error function defined in the least square sense as the weighted gap between experimental and computed data. The observable variables accounted for in the error function are the stress and strain components. The weights were chosen according to the uncertainty of the experimental data and therefore depend on the experimental type of test (tensile, shear, bulge) as detailed in Zang et al. (2011).

Furthermore, anisotropic yield function parameters $(L, M)$ for Hill's 1948 function and $c_{5,6}^{k}$ for Bron\&Besson function are related to shear in the sheet thickness. Experimental data allowing to identify these parameters was not available and they were consequently kept constant and equal to isotropic values, $\mathrm{L}=\mathrm{M}=3$ and $c_{5,6}^{k}=1$. Additionally, since $\mathrm{H}+\mathrm{G}=2$, only one of these two parameters needs to be identified.

In order to achieve a good description of the overall experimental database with a single parameter set, the following strategy was used:

- initial isotropic hardening parameters and a yield stress, $\sigma_{s a t}, C_{R}, n$, $\sigma_{0}$, were identified considering the three tensile tests and the monotonic 
- yield surface shape parameters, $\lambda, a, b_{1}, b_{2}$ of the Bron\&Besson yield function were approximated using the balanced biaxial tension test,

- as mixed hardening is considered, both kinematic hardening parameters, $B_{X}, C_{X}, H_{X}$ and isotropic hardening parameters were identified on cyclic shear tests,

- anisotropy parameters, $c_{i=1.4}^{k=1,2}$ for the Bron\&Besson yield function and $F, G, N$ for Hill's 1948 yield function were identified considering the whole database.

The resulting material parameters for the phenomenological model are listed in Table 2, Table 3 and Table 4.

\begin{tabular}{ccccc}
\hline$E$ & $\nu$ & $K_{v}$ & $n_{v}$ & $\sigma_{0}$ \\
\hline 95. & 0.37 & 74.2 & 30.1 & 290. \\
\hline
\end{tabular}

Table 2: Material parameters common to both yield functions. $E$ is in $\mathrm{GPa}, \sigma_{0}$ in $\mathrm{MPa}$ while $K_{v}$ is in MPa.s ${ }^{n^{-1}}$.

Up to three Armstrong-Frederick kinematic hardening terms had to be added to achieve an accurate description as suggested in Chaboche (1991).

\begin{tabular}{ccccccccccc}
\hline$F$ & $G$ & $H=2-G$ & $N$ & & & & & & \\
1.01 & 0.83 & 1.17 & 3.41 & & & & & & \\
\hline$C_{X_{1}}$ & $B_{X_{1}}$ & $C_{X_{2}}$ & $B_{X_{2}}$ & $C_{X_{3}}$ & $B_{X_{3}}$ & $H_{X}$ & $\sigma_{\text {sat }}$ & $C_{R}$ & $n_{r}$ \\
13400 & 293 & 238 & 0.01 & 2850 & 60.4 & 395 & 5420 & 0.16 & 1.38 \\
\hline
\end{tabular}

Table 3: Material parameters for Hill's 1948 yield function. $C_{X_{i}}, H_{X}$ and $\sigma_{s a t}$ are in MPa. 


\begin{tabular}{cccccccccc}
\hline$a$ & $b_{1}$ & $b_{2}$ & $\lambda$ & & & & & & \\
49.2 & 2.1 & 12.7 & 0.2 & & & & & & \\
\hline$c_{11}$ & $c_{12}$ & $c_{13}$ & $c_{14}$ & $c_{21}$ & $c_{22}$ & $c_{23}$ & $c_{24}$ & & \\
1.1 & 0.8 & 1.01 & 1.1 & 0.5 & 1.3 & 0.6 & 0.9 & & \\
\hline$C_{X_{1}}$ & $B_{X_{1}}$ & $C_{X_{2}}$ & $B_{X_{2}}$ & $C_{X_{3}}$ & $B_{X_{3}}$ & $H_{X}$ & $\sigma_{\text {sat }}$ & $C_{R}$ & $n_{r}$ \\
5080 & 243 & 44.8 & 0.1 & 2190 & 52 & 336 & 2820 & 0.23 & 1.21 \\
\hline
\end{tabular}

Table 4: Material parameters for Bron\&Besson yield function. $C_{X_{i}}, H_{X}$ and $\sigma_{\text {sat }}$ are in $\mathrm{MPa}$.

279 The material presents a noticeable stress anisotropy as tensile strain-stress 280 curves at $45^{\circ} / \mathrm{RD}$ and $90^{\circ} / \mathrm{RD}$ are nearly superposed but the stress level at $0^{\circ} / \mathrm{RD}$ is clearly higher. Bron\&Besson model captured this feature well while Hill's 1948 model failed to represent the stress anisotropy as shown in Fig. 4.

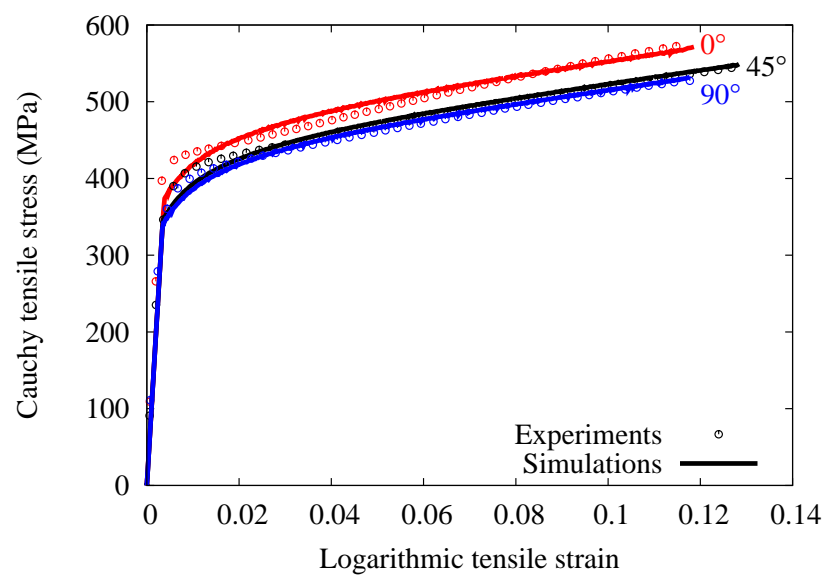

(a) Bron\&Besson

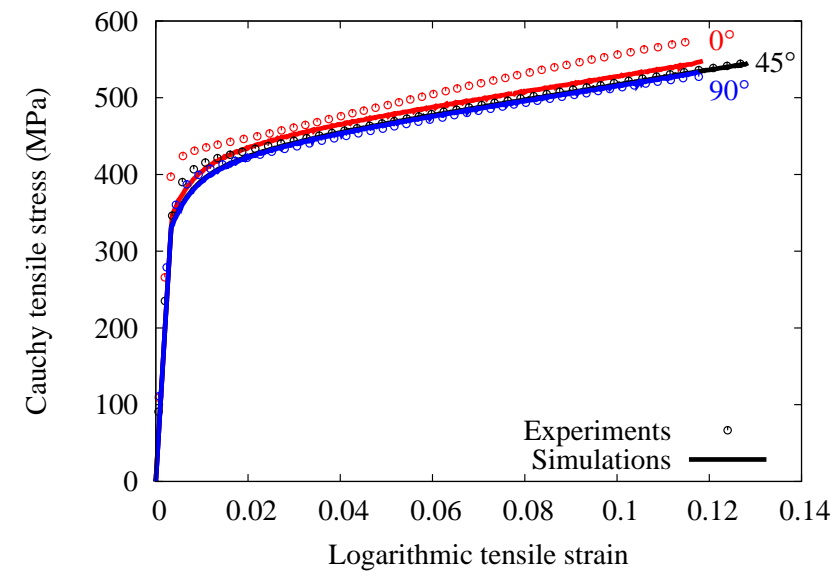

(b) Hill

Figure 4: Prediction of the tensile tests at $0^{\circ}, 45^{\circ}$ and $90^{\circ}$ with the phenomenological model using the yield functions of a) Bron\&Besson and b) Hill's 1948. Symbols show the experimental values.

Both models performed well in balanced biaxial tension and shear test description as illustrated in Fig. 5 and Fig. 6, although the Bron\&Besson model predictions were slightly closer to the experiments. 


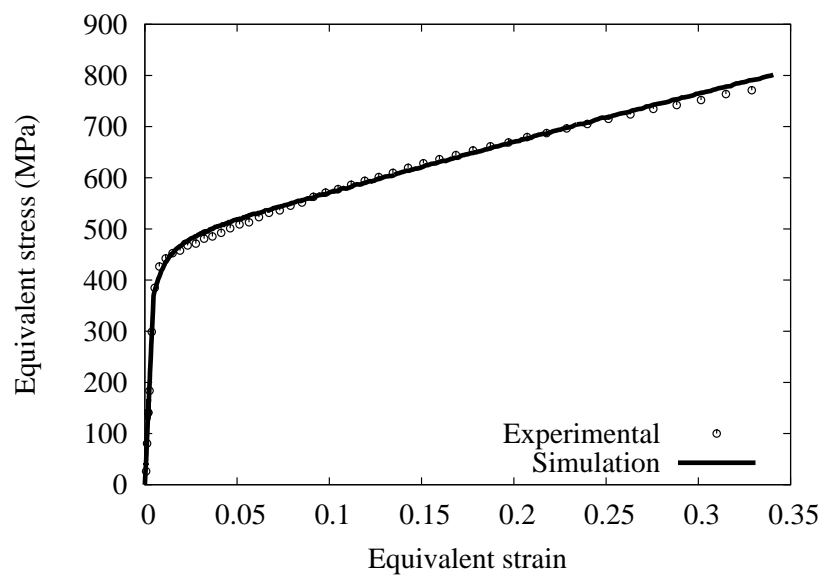

(a) Bron\&Besson

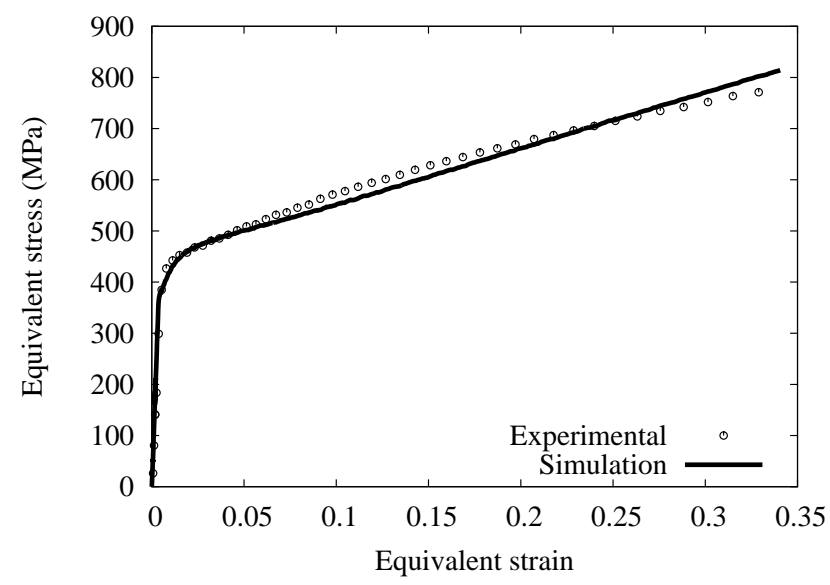

(b) Hill

Figure 5: Prediction of the hydraulic bulge tests with the phenomenological model using the yield functions of a) Bron\&Besson and b) Hill's 1948. Symbols show the experimental values.

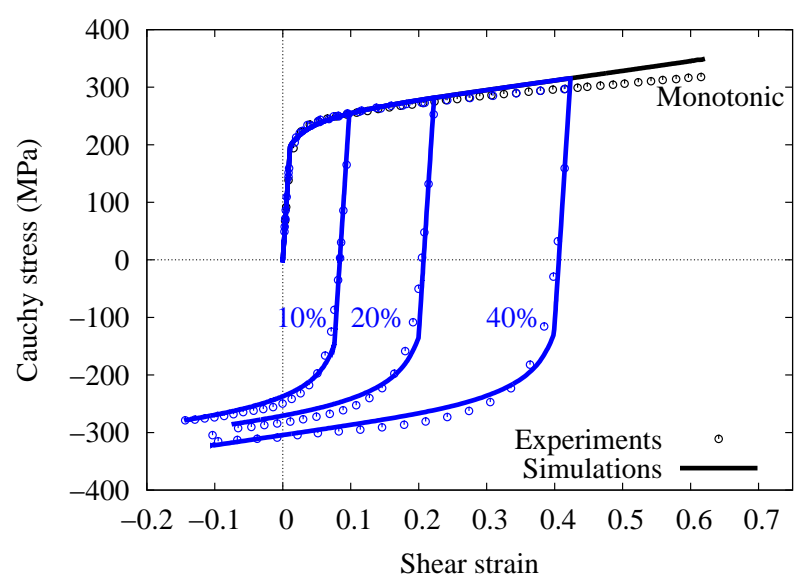

(a) Bron\&Besson

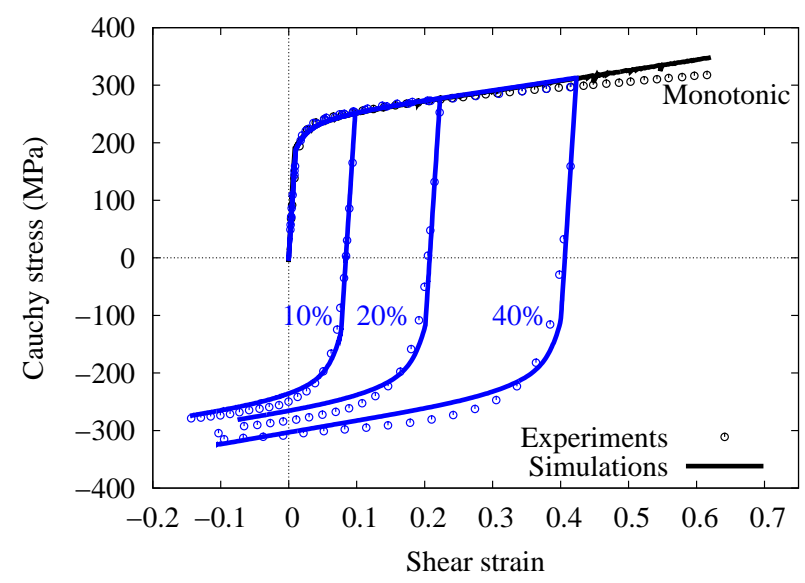

(b) Hill

Figure 6: Prediction of the monotonic and reversed shear tests with the phenomenological model using the yield functions of a) Bron\&Besson and b) Hill's 1948. Symbols show the experimental values. 


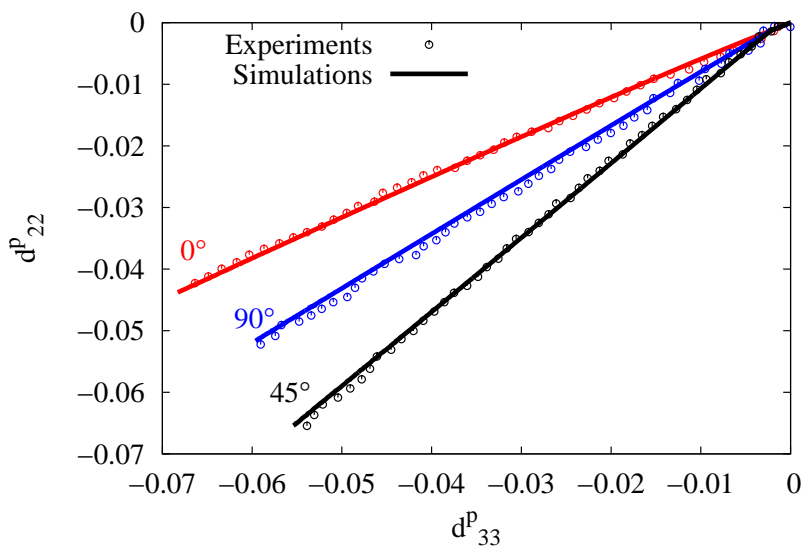

(a) Bron\&Besson

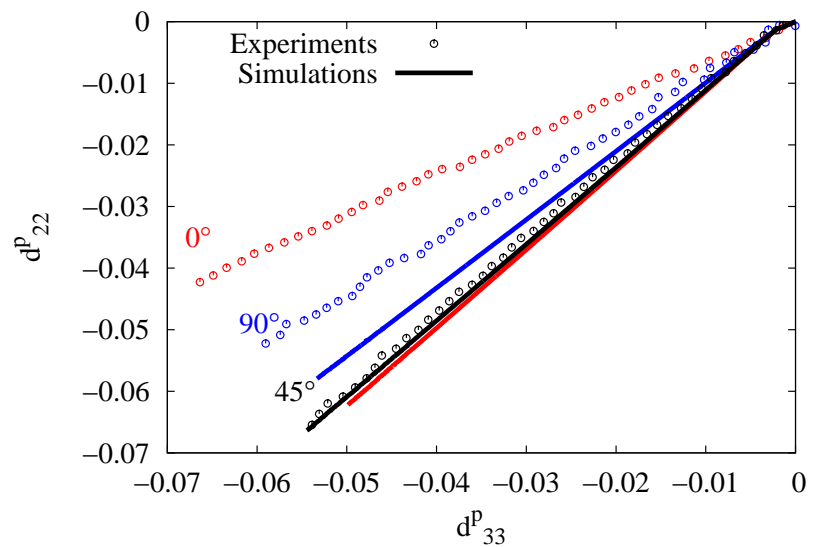

(b) Hill

Figure 7: Prediction of the plastic anisotropy ratios with the phenomenological model using the yield functions of a) Bron\&Besson and b) Hill's 1948. Symbols show the experimental values.

Concerning strain anisotropy, Hill's model did not adequately render the material feature and only $r_{45}$ was well described. Due to its eight dedicated anisotropy parameters, Bron\&Besson model performed remarkably as well in the strain anisotropy, see Fig. 7, as in the stress levels description.

However in both cases one has to deal with a high number of parameters, 19 for Hill's 1948 model and 28 for Bron\&Besson, throughout a non linear and relatively complex identification procedure.

\section{CPFEM model and corresponding parameter identification strate- gies}

The alternative modeling framework adopted in this work is based on the rate-dependent theory of crystal plasticity. The rate-dependent or viscoplastic formulation was adopted as the material presents a certain strain rate sensitivity as shown in Fig. 3 but also because of its numerical efficiency and robustness when compared to rate-independent formulation. 


\subsection{Single crystal kinematics and plastic flow}

The single crystal plasticity model is based on the works of Rice (1971), Peirce et al. (1982), Needleman et al. (1985), Raphanel et al. (2004) and its equations are recalled here for the sake of completeness. The formalism presented below stands for the general theory of crystal plasticity, regardless of any aspect of numerical implementation.

The classical multiplicative breakdown of the deformation gradient is adopted:

$$
\mathbf{F}=\mathbf{F}^{e} \cdot \mathbf{F}^{p}
$$

where $\mathbf{F}^{p}$ represents plastic deformation of matter through the lattice resulting from shearing along activated slip-systems and $\mathbf{F}^{e}$ corresponds to crystal lattice rigid rotation and its elastic stretching while all slip movement is assumed to be frozen.

The velocity gradient $\mathbf{L}=\dot{\mathbf{F}} \cdot \mathbf{F}^{-1}$ can then be expressed as:

$$
\mathbf{L}=\mathbf{L}^{e}+\mathbf{L}^{p} \text { where } \mathbf{L}^{e}=\dot{\mathbf{F}}^{e} \cdot \mathbf{F}^{e^{-1}} \text { and } \mathbf{L}^{p}=\mathbf{F}^{e} \cdot \mathbf{L}_{i}^{p} \cdot \mathbf{F}^{e^{-1}}
$$

The velocity gradient in the intermediate configuration $\mathbf{L}_{i}^{p}$ is related to crystallographic slip by:

$$
\mathbf{L}_{i}^{p}=\dot{\mathbf{F}}^{p} \cdot \mathbf{F}^{p^{-1}}=\sum_{s=1}^{12} \dot{\gamma}^{(s)} \mathbf{S}_{0}^{(s)} \text { with } \mathbf{S}_{0}^{(s)}=\mathbf{m}_{0}^{(s)} \otimes \mathbf{n}_{0}^{(s)},
$$

where $\dot{\gamma}^{(s)}$ is the shearing slip rate on the slip sytem (s) defined by the slip direction $\mathbf{m}^{(s)}$ and the slip plane normal $\mathbf{n}^{(s)}, \mathbf{S}_{0}^{(s)}$ being the Schmid tensor in the reference and intermediate configuration. The subscript ' 0 ' stands for tensorial quantities expressed in the reference configuration. Twelve slip systems were considered for the studied copper alloy of FCC structure.

The rate of deformation $\mathbf{D}$ and spin $\mathbf{W}$ tensors, which are the symmetric and skew-symetric part of the velocity gradient $\mathbf{L}$, can be splitted in elastic and plastic components as:

$$
\mathbf{D}=\mathbf{D}^{e}+\mathbf{D}^{p} \text { with } \mathbf{D}^{p}=\sum_{i=1}^{12} \dot{\gamma}^{(s)} \mathbf{D}^{(s)}
$$

and

$$
\mathbf{W}=\mathbf{W}^{e}+\mathbf{W}^{p} \quad \text { with } \quad \mathbf{W}^{p}=\sum_{i=1}^{12} \dot{\gamma}^{(s)} \mathbf{W}^{(s)} .
$$


In the above equations, $\mathbf{D}^{(s)}=\operatorname{sym}\left(\mathbf{S}^{(s)}\right)$ and $\mathbf{W}^{(s)}=\operatorname{skew}\left(\mathbf{S}^{(s)}\right)$ where $\mathbf{S}^{(s)}=$ $\mathbf{m}^{(s)} \otimes \mathbf{n}^{(s)}$ is the Schmid tensor of slip system (s) in the current configuration, and 'sym' and 'skew' designate the symmetric and skew-symmetric part of the given tensor, respectively.

The slip direction vector and the slip plane normal in the current configuration are convected from their counterparts in the reference configuration by means of the elastic deformation gradient:

$$
\mathbf{m}^{(s)}=\mathbf{F}^{e} \cdot \mathbf{m}_{0}^{(s)} \text { and } \mathbf{n}^{(s)}=\mathbf{n}_{0}^{(s)} \cdot \mathbf{F}^{e} .
$$

Plastic flow occurs on a slip system if the resolved shear stress $\tau^{(s)}$ exerted on this system is greater than its resistance to slip, the critical resolved shear stress $\tau_{c}^{(s)}$. The resolved shear stress is calculated with the generalized Schmid law:

$$
\tau^{(s)}=\mathbf{m}^{(s)} \cdot \boldsymbol{\sigma} \cdot \mathbf{n}^{(s)}=\boldsymbol{\sigma}: \mathbf{D}^{(s)} .
$$

According to the rate-dependent formulation, the slip rates can be explicitly computed by the plastic flow rule

$$
\dot{\gamma}^{(s)}=\left\{\begin{array}{ll}
\dot{\gamma}_{0}^{(s)} \operatorname{sign}\left(\tau^{(s)}\right)\left|\frac{\tau^{(s)}}{\tau_{c}^{(s)}}\right|^{n} & \text { if }\left|\tau^{(s)}\right| \geq \tau_{c}^{(s)} \\
0 & \text { if } \tau^{(s)}<\tau_{c}^{(s)}
\end{array},\right.
$$

where $\dot{\gamma}_{0}^{(s)}$ is the reference shear strain rate and $n$ is the strain rate sensitivity coefficient.

If one assumes an hypoelasticity formalism, the constitutive equation in the global frame can be written in terms of the rate of deformation tensor and its work-conjugate stress measure Kirchhoff tensor $\boldsymbol{\tau}$ as:

$$
\hat{\boldsymbol{\tau}}^{e}=\mathbf{C}: \mathbf{D}^{e}=\mathbf{C}:\left(\mathbf{D}-\mathbf{D}^{p}\right),
$$

where $\hat{\boldsymbol{\tau}}^{e}$ is the Jaumann derivative of stress based on crystal lattice spin tensor $\mathbf{W}^{e}$ and $\mathbf{C}$ is the elastic modulus tensor.

When considering the Jaumann stress rate related to the spin tensor $\mathbf{W}$, this equation can be rewritten in terms of Cauchy stress as:

$$
\dot{\boldsymbol{\sigma}}=\mathrm{C}: \mathrm{D}+\mathbf{W} \cdot \boldsymbol{\sigma}-\boldsymbol{\sigma} \cdot \mathbf{W}-\boldsymbol{\sigma} \operatorname{tr}(\mathrm{D})-\left(\mathbf{C}: \mathbf{D}^{p}+\mathbf{W}^{p} \cdot \boldsymbol{\sigma}-\boldsymbol{\sigma} \cdot \mathbf{W}^{p}\right)
$$

where $\dot{\boldsymbol{\sigma}}$ stands for the time derivative of $\boldsymbol{\sigma}$.

As straining occurs, material properties evolve. The common generic hardening model on the slip systems is expressed as

$$
\dot{\tau}_{c}^{(s)}=H_{s \beta} \dot{\gamma}^{\beta}
$$


where $H_{s \beta}$ are the components of the hardening matrix. In this work, we will consider the expression proposed by Peirce et al. (1983) and usually termed as the PAN (for Peirce Asaro Needleman) model. More accurate models are available in the literature where hardening is explicitly linked to dislocation density based internal variables (Tabourot (1992)). A comparative study of such models with PAN-type models can be found in Lee et al. (2010).

The hardening matrix used in this work reads:

$$
H_{s \beta}=\left[q+(1-q) \delta_{s \beta}\right] h(\gamma), \text { with } h(\gamma)=h_{0} \operatorname{sech}^{2}\left(\frac{\mathrm{h}_{0} \gamma}{\tau^{*}-\tau_{0}}\right),
$$

where $\delta_{s \beta}$ is the Kronecker delta, $q$ is the latent hardening parameter, $\gamma=$ $\int \sum_{s} \dot{\gamma}^{(s)} d t$ is the cumulated glide on all slip systems, $h_{0}$ is the initial hardening slope, $\tau^{*}$ relates to a saturation shear stress and $\tau_{0}$ is the initial critical resolved shear stress.

Additionaly, straining induces large rotations and subsequent reorientation of the crystals. Within the formalism used here, the evolution of the crystal orientation matrix can be expressed in an incremental way as:

$$
\dot{\mathbf{Q}}=\mathbf{W}^{e} \cdot \mathbf{Q}=\left(\mathbf{W}-\mathbf{W}^{p}\right) \cdot \mathbf{Q} .
$$

\subsection{Finite element implementation}

The elastic-viscoplastic $\mathrm{CP}$ model was further implemented in the FE code ABAQUS/Explicit. In this code, the default coordinate system is the corotationnal frame (Hibbitt (1992)) associated with the Green-Naghdi objective derivative. This frame is generated by the rotation tensor $\mathbf{R}$ calculated from the polar decomposition of the deformation gradient:

$$
\mathbf{F}=\mathbf{R} \cdot \mathbf{U}
$$

where $\mathbf{U}$ is the right stretch tensor.

Thus for crystal plasticity implementation, three coordinate systems should be distinguished : the global frame, the Crystal lattice Axes Coordinate System (C.A.C.S) and the additional system defined above termed as the Material Element Coordinate System (M.E.C.S.), see Fig. 8.

Although only the fixed and crystal frames are involved in the theoretical model, efficiency can be improved by considering an implementation in the rotating objective space frames, namely the MECS and the CACS (Amirkhizi and Nemat-Nasser (2007)). 


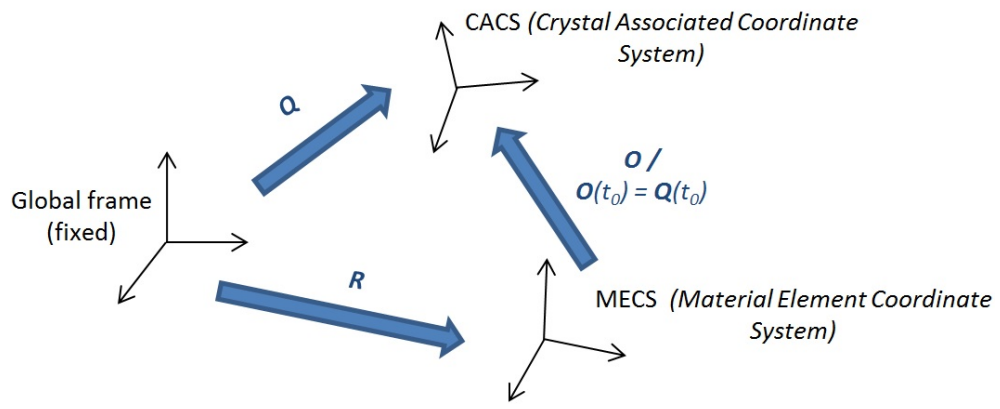

Figure 8: Different frames and associated rotation matrices for crystal plasticity implementation in ABAQUS/Explicit

Several other authors Guan et al. (2006), Zamiri et al. (2007), Li et al. (2008), Rousselier et al. (2009), Segurado et al. (2012), Zhang et al. (2012) have proposed procedures to achieve finite element implementations in objective space frames. The algorithm adopted here is summarized in Table 5. Except for orientation update, numerical integration of rate equations was performed with explicit Runge-Kutta integration schemes of orders 1, 2 and 4. It has been confirmed, (Haddag et al. (2007), Franz et al. (2009)), that for constitutive models with a large number of internal variables, explicit integration schemes represent a good compromise between efficiency and accuracy. In the applications presented in this paper, the first order proved as accurate and robust as the second and fourth order Runge-Kutta scheme while being much more efficient. The Euler explicit scheme has also been tested in CPFEM by Grujicic and Batchu (2002), Dumoulin et al. (2009) and Dumoulin et al. (2012), Zhang et al. (2014) with very good results. Orientation update was performed using the method of Raphanel et al. (2004) in order to ensure that computed rotation matrices remain orthogonal.

In the remaining part of the paper and unless specified otherwise, quantities expressed in the CACS are indicated with a tilde while those in the MECS carry no distinctive symbol for the sake of clarity.

\subsection{Parameter identification}

The parameter identification was conducted while simulating experimental tests on Representative Volume Elements (RVE). The concept of RVE (e.g. Kanit et al. (2003), Gitman et al. (2007)) bridges the gap between the crystal scale and the macroscopical scale. Consistent comparisons can thus 
- Initialise rotation matrix from CACS to MECS $\mathbf{O}_{t=0}=\mathbf{Q}_{0}$

- Input : $\boldsymbol{\sigma}_{n}, \mathbf{U}_{n+1}, \mathbf{U}_{n}$

Variables : $\tilde{\boldsymbol{\sigma}}_{n}, \mathbf{O}_{n}, \tilde{\mathbf{F}}_{n}^{p}, \tilde{\mathbf{F}}_{n}^{e}, \tau_{c_{n}}^{(s=1 . .12)}, \gamma_{n}, \mathbf{Q}_{n}$

- Compute $\mathbf{D}_{n+1}=\operatorname{sym}\left(\dot{\mathbf{U}} \mathbf{U}_{n+1}^{-1}\right)$

- Rotation to CACS $\tilde{\mathbf{D}}_{n+1}=\mathbf{O}_{n}^{T} \mathbf{D}_{n+1} \mathbf{O}_{n} \quad ; \quad \tilde{\mathbf{U}}_{n+1}=\mathbf{O}_{n}^{T} \mathbf{U}_{n+1} \mathbf{O}_{n}$

- Update (for s=1..12) $\tilde{\mathbf{S}}_{n}^{s}=\tilde{\mathbf{F}}_{n}^{e} \tilde{\mathbf{S}}_{c}^{s} \tilde{\mathbf{F}}_{n}^{e^{-1}} ; \tilde{\mathbf{M}}_{n}^{s}=\operatorname{sym}\left(\tilde{\mathbf{S}}_{n}^{s}\right)$

- Compute (for $\mathrm{s}=1 . .12) \quad \tau_{n+1}^{s}=\tilde{\boldsymbol{\sigma}}_{n}: \tilde{\mathbf{M}}_{n}^{s} \quad ; \quad \dot{\gamma}_{n+1}^{s}$ with $\operatorname{Eq}(24)$

- Update $\tilde{\mathbf{F}}_{n+1}^{p}=\tilde{\mathbf{F}}_{n}^{p}+\Delta t\left(\mathbf{I}+\sum_{s=1}^{12} \dot{\gamma}_{n+1}^{s} \tilde{\mathbf{S}}_{c}^{s}\right) ; \quad \tilde{\mathbf{F}}_{n+1}^{e}=\tilde{\mathbf{U}}_{n+1} \tilde{\mathbf{F}}_{n+1}^{p^{-1}}$

- Update (for s=1..12) $\tilde{\mathbf{S}}_{n+1}^{s}=\tilde{\mathbf{F}}_{n+1}^{e} \tilde{\mathbf{S}}_{c}^{s} \tilde{\mathbf{F}}_{n+1}^{e^{-1}}$;

$\tilde{\mathbf{M}}_{n+1}^{s}=\operatorname{sym}\left(\tilde{\mathbf{S}}_{n+1}^{s}\right) \quad ; \quad \tilde{\mathbf{W}}_{n+1}^{s}=\operatorname{skew}\left(\tilde{\mathbf{S}}_{n+1}^{s}\right)$

- Compute $\tilde{\mathbf{D}}_{n+1}^{p}=\sum_{s=1}^{12} \dot{\gamma}_{n+1}^{s} \tilde{\mathbf{M}}_{n+1}^{s} \quad ; \quad \tilde{\mathbf{W}}_{n+1}^{p}=\sum_{s=1}^{12} \dot{\gamma}_{n+1}^{s} \tilde{\mathbf{W}}_{n+1}^{s}$

- Update

$\tilde{\boldsymbol{\sigma}}_{n+1}=\tilde{\boldsymbol{\sigma}}_{n}+\Delta t\left[\mathbf{C}:\left(\tilde{\mathbf{D}}_{n+1}-\tilde{\mathbf{D}}_{n+1}^{p}\right)-\tilde{\boldsymbol{\sigma}}_{n} t r\left(\tilde{\mathbf{D}}_{n+1}\right)\right]$

- Update (for $\mathrm{s}=1 . .12) \quad \tau_{c_{n+1}}^{s}=\tau_{c_{n}}^{s}+\Delta t\left(\sum_{p=1}^{12} h^{s p} \dot{\gamma}^{p}\right)$

- Update $\mathbf{O}_{n+1}=\exp \left[\Delta t\left(\tilde{\mathbf{W}}^{p}\right)\right] \mathbf{O}_{n}$ (Euler-Rodrigues formula)

- Rotation to MECS $\boldsymbol{\sigma}_{n+1}=\mathbf{O}_{n+1} \tilde{\boldsymbol{\sigma}}_{n+1} \mathbf{O}_{n+1}^{T}$

Table 5: Algorithm for the time integration of the crystal plasticity constitutive model. 
be performed.

The numerical microstructure was generated using a Laguerre tessellation (Quey et al. (2011)). Grain diameters were considered as weights and a normal distribution employed with the mean grain size and the standard deviation as parameters. The microstructure was specified to be periodic. Each grain was meshed with at least 20 solid reduced integration finite elements, in order to guarantee sufficient accuracy for the prediction of the macroscopic response (Diard et al. (2005), Lin et al. (2010), Belkhabbaz et al. (2015)). The orientations attributed to the grains were obtained following a two step procedure. First, the experimental orientation data (4460 triplets of Euler angles) from EBSD were converted in an Orientation Distribution Function (ODF) using the grain diameter as weights (Tarasiuk et al. (2004)). Then the continuous distribution was discretised into the number of desired individual crystallographic orientations. We thereby ensured that our volume elements statiscally represented the experimental texture even with few orientations. Experimental pole figures and numerically sampled ones are compared in Fig. 9. The numerical texture replicated the main characteristics of the experimental data.

Periodic Boundary Conditions were applied to the virtual volume elements. Tensile tests were simulated on cuboid volume elements of increasing size with 100, 200, 300, 400, 500, 600, 700, 800 grains in order to determine the required size to be representative of the macroscopic behavior. Again, the studied sheet metals were purposely chosen with enough thickness grains to enable analysis with both phenomenological and CPFEM based models.

The macroscopic stresses and strains were obtained by averaging the corresponding local values over the total volume. The convergence analysis, see Fig. 10, revealed that above 500 grains, the scatter in the volume elements macroscopic responses was negligible and a Representative Volume Element can therefore be set up from a volume element with 500 grains.

The parameters of the P.A.N model were identified with respect to the experimental tensile test performed in the rolling direction. Indeed through representation of material texture, anisotropy features are inherently accounted for. Thus, only a few parameters had to be adjusted and no other experimental test was required in the present calibration procedure. Flow rule parameters, $\dot{\gamma}_{o}$ and $n$, are usual material values for room temperature Copper that can be found in the literature (Tabourot (2001)). Hardening matrix parameters, $h_{0}, q, \tau^{*}$ and $\tau_{0}$ are calibrated with respect to the RD tensile test. As illustrated in Fig. 11, a good agreement was obtained between the 
(100)

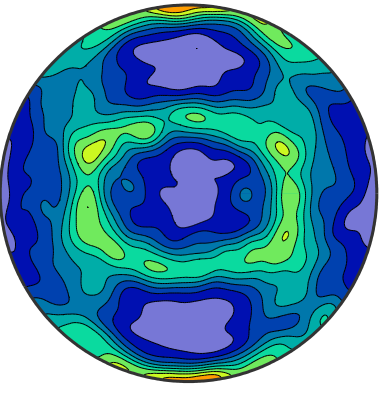

(100)

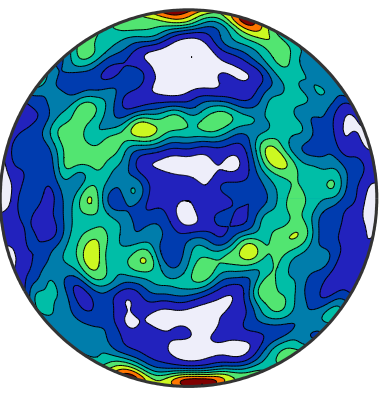

(110)

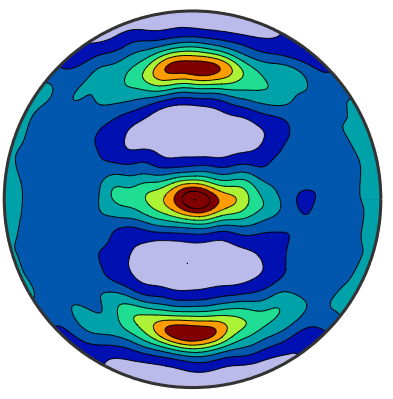

(a) Experimental (110)

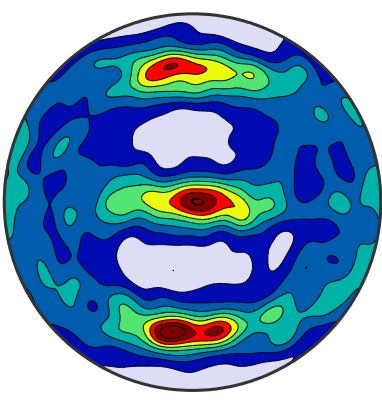

(111)

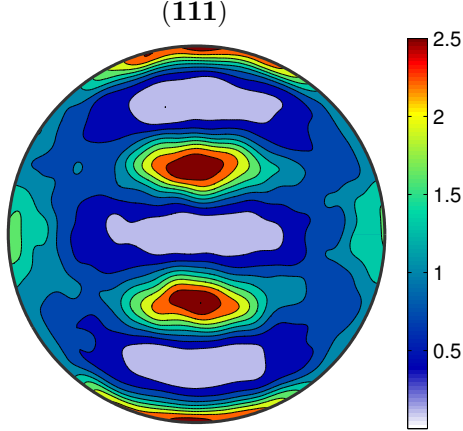

(111)

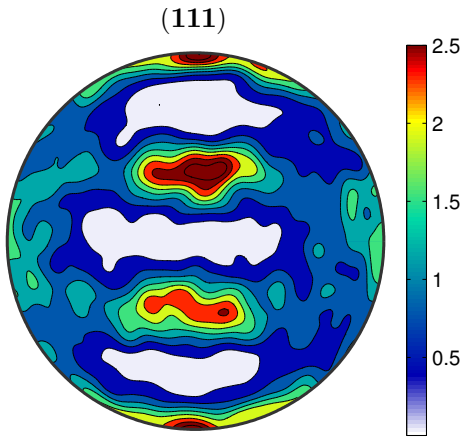

(b) Numerical

Figure 9: Pole figures obtained from a) EBSD experiments orientation data and b) numerically sampled orientations for the RVE.

experiment and the simulated curve although the elastic-plastic transition could not be perfectly captured. It is worth noting that the phenomenological models were also unable to describe this specific detail of the experimental data set. This feature may be an effect of the cold rolling pre-strain which is not taken into account in any of the models.

\section{Comparison of both approaches and discussion}

\subsection{Models descriptions for various strain paths}

Tensile tests at $45^{\circ}$ and $90^{\circ}$ from the R.D. were simulated with the calibrated PAN model. The microstructure was numerically rotated by decreasing the RD corresponding Euler angle of the desired value $\left(45^{\circ}\right.$ and $\left.90^{\circ}\right)$ while 

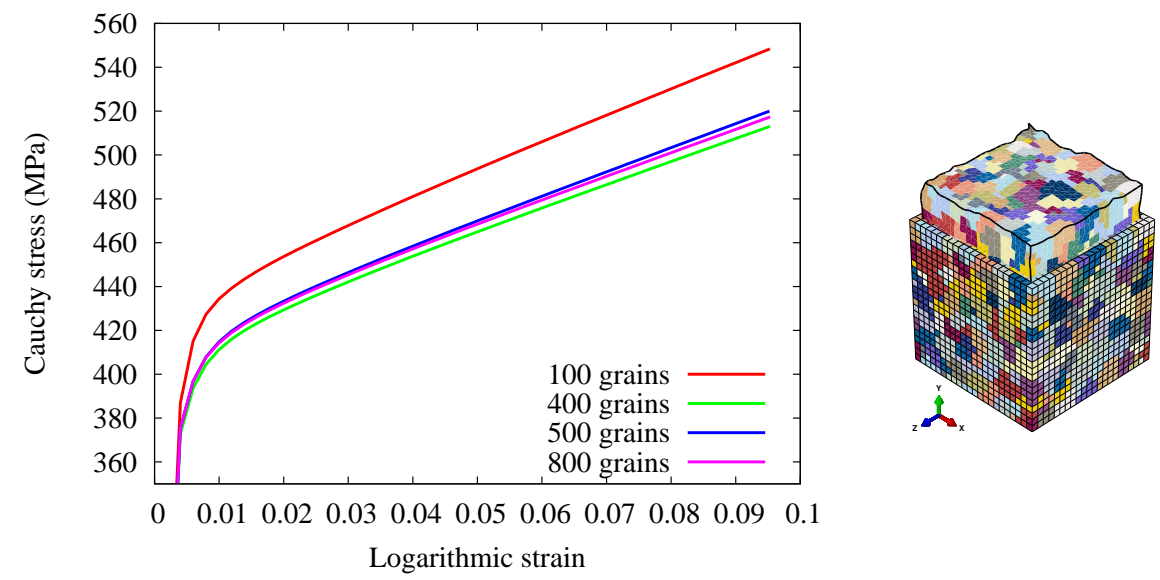

Figure 10: Convergence analysis on Volume Elements for a CPFEM simulated tensile test in the RD. The RVE is shown on the right, prior to straining (with the mesh) and after deformation. The color of the grains is not related to their orientation.

(Model parameters : $h_{0}=300 \mathrm{MPa}, \tau^{*}=750 \mathrm{MPa}, \tau_{0}=250 \mathrm{MPa}, q=1.4, \dot{\gamma}_{o}=0.001 \mathrm{~s}^{-1}$, $n=50)$

\begin{tabular}{cccccc}
$h_{0}(\mathrm{MPa})$ & $\tau^{*}(\mathrm{MPa})$ & $\tau_{0}(\mathrm{MPa})$ & $q$ & $\dot{\gamma}_{o}\left(\mathrm{~s}^{-1}\right)$ & $n$ \\
\hline 100 & 700 & 175 & 1.4 & 0.001 & 50. \\
\hline
\end{tabular}

Table 6: Material parameters for CPFEM calibrated on a tensile test in the RD.

the mesh and the boundary conditions remain unchanged. This methodology proved relevant for quasi equiaxed grains (Zhang et al. (2015)) as is the case in the present work.

The simulated curves match closely with the experimental ones as can be seen in Fig. 12 and Fig. 13, both in the elastic-plastic transition zone and at higher strains, even though a little deviation arises at the very end of the $90^{\circ} / \mathrm{RD}$ curve.

Thus, using hardening parameters calibrated on a single tensile test in the $\mathrm{RD}$, a good description of stress anisotropy was achieved with the CPFEM approach as the texture was accounted for.

The CPFEM model's predictions under balanced biaxial tensile loading are 


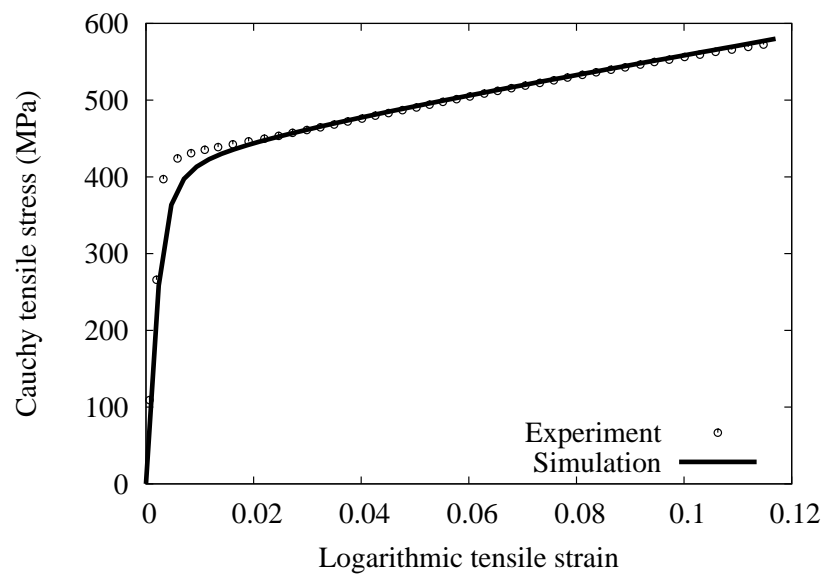

Figure 11: CPFEM model identification on the $0^{\circ} / \mathrm{RD}$ tensile test.

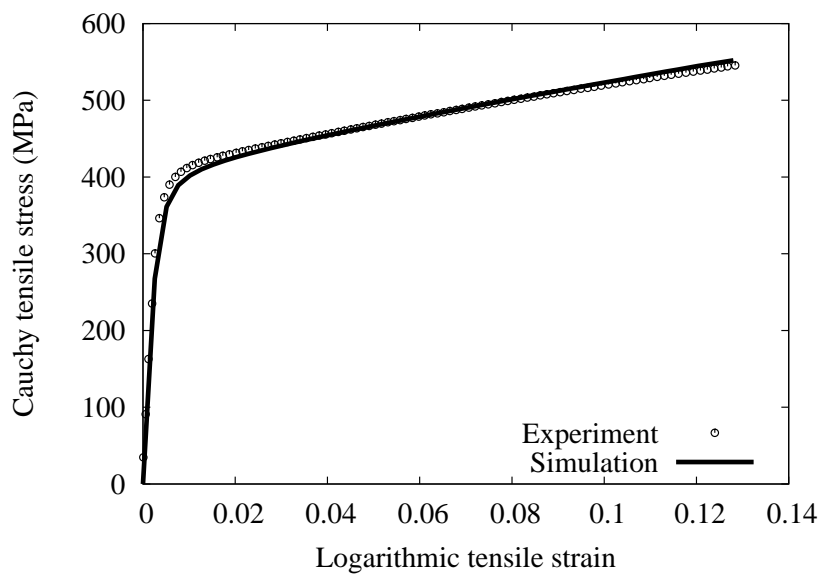

Figure 12: Experimental and CPFEM model simulated tensile curves at $45^{\circ} / \mathrm{RD}$.

shown in Fig. 14. A good agreement was obtained between experimental and simulated curves. It is worth noting that the strain level used for this validation is three times larger than the strain level used for the parameter identification of the hardening model. Shear test in the RD, as well as reverse shear tests at different pre-strain ranges were also simulated. The response 


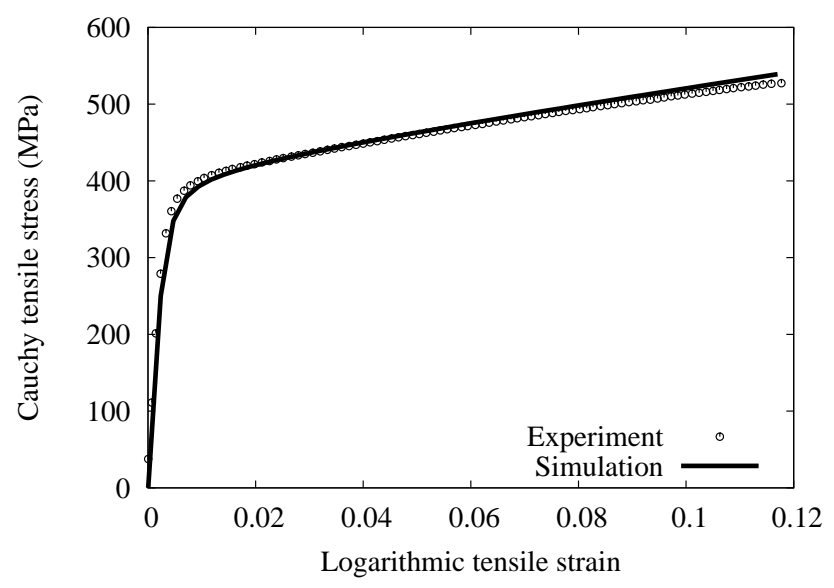

Figure 13: Experimental and CPFEM model simulated tensile curves at 90\% $/ \mathrm{RD}$.

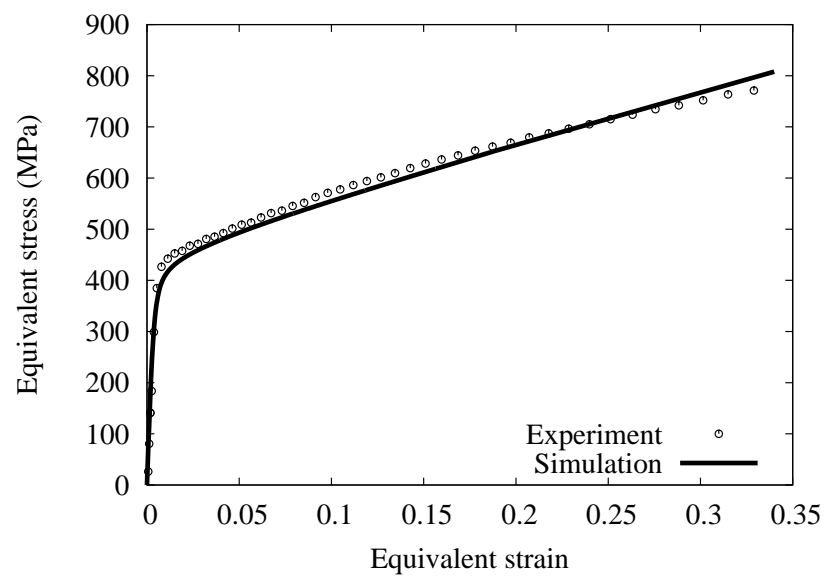

Figure 14: Experimental and CPFEM model simulated responses to equi-biaxial tensile loading.

under monotonic shearing was well reproduced, see Fig. 15, nevertheless the predicted hardening rate being larger than the experimental one. Again, similar behavior was also predicted with the phenomenological model, see Fig. 6. The Bauschinger effect and permanent softening induced after strain 


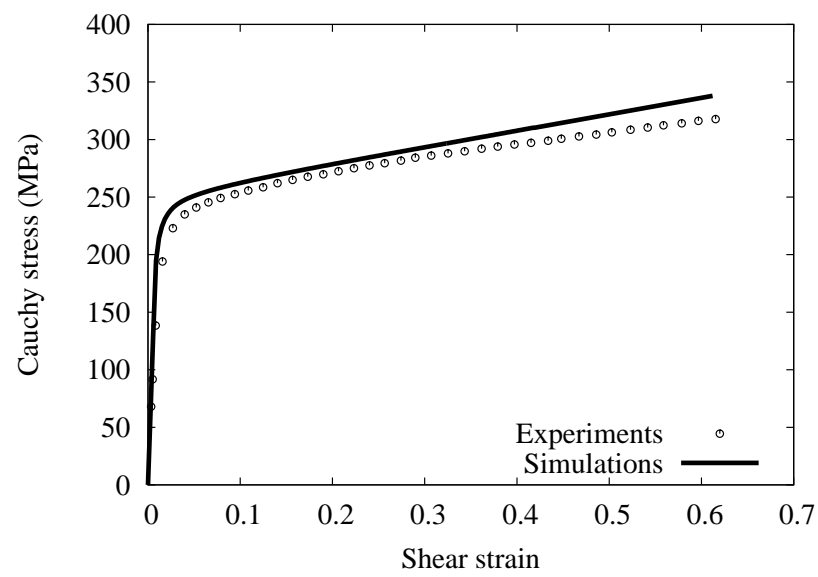

Figure 15: Experimental and CPFEM model simulated responses to monotonic shear loading.

path reversal were underestimated quite significantly by the CPFEM model as shown in Fig. 16.

In order to more accurately describe material response during strain reversal, several authors (Cailletaud (1992), Li et al. (2012)) introduce a kinematic hardening variable in the flow rule at the slip system level. That variable evolution is governed by an Armstrong-Frederick type law and its material parameters have to be fitted on cyclic tests. A different approach was proposed by Balland et al. (2011) which requires relatively less effort for identification. Different initial critical resolved shear stresses are distributed in the grains of the aggregate. Thereby stress inhomogeneity, which can be linked to such material behavior, is introduced in the model. A Rayleigh distribution was adopted to model an inhomogeneous repartition of the initial critical resolved shear stress in the aggregate. It is written as:

$$
f\left(\tau_{o}\right)=\frac{\tau_{o}}{\left(\tau_{0}^{h o m}\right)^{2}} \exp \left(\frac{-\left(\tau_{o}\right)^{2}}{2\left(\tau_{0}^{h o m}\right)^{2}}\right),
$$

where the modal of the distribution $\tau_{0}^{h o m}$ is chosen equal to the previously identified initial critical resolved shear stress $\tau_{0}$.

The latter approach proved successful for pre-strains up to $20 \%$ as can 
be seen in Fig. 17. However when the pre-strain is larger, the model still underestimates the Bauschinger effect and permanent softening induced.

These results tend to show that intergranular stress inhomogeneity may

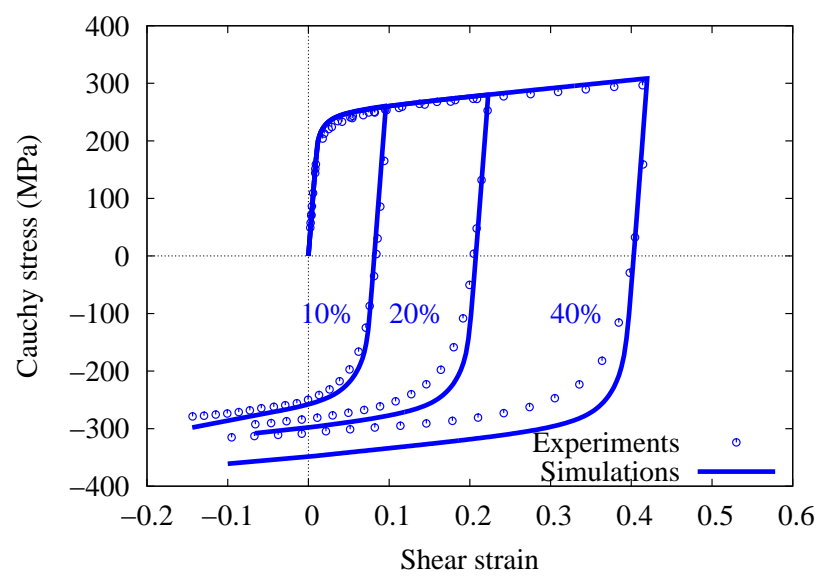

Figure 16: Experimental reversed shear test and CPFEM model simulated curves.

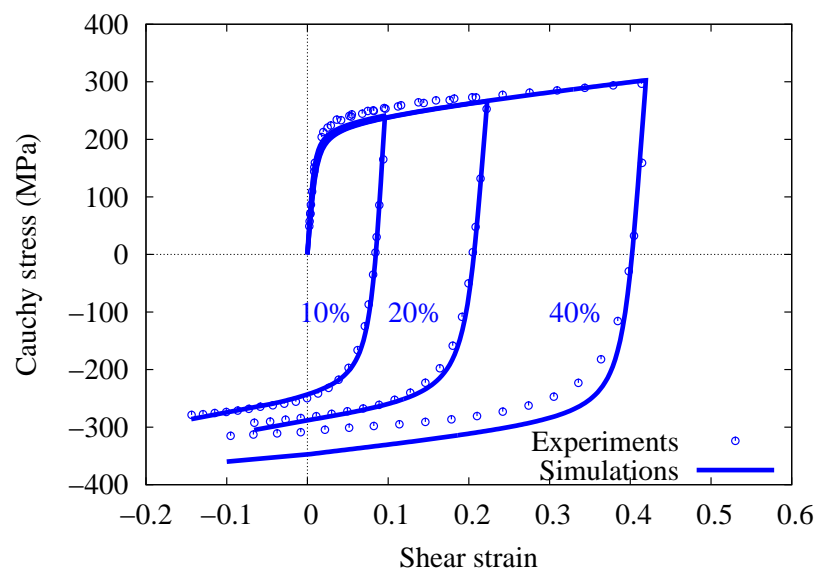

Figure 17: Experimental reversed shear test and CPFEM model simulated curves while accounting for initial stress inhomogeneity. 
be sufficient to describe strain reversal behavior up to moderate pre-strain levels. Afterwards, the effect of intragranular backstress cannot be neglected and the hardening model needs further improvements (Kim et al. (2012), Li et al. (2014)).

\subsection{Phenomenological models calibration with a reduced experimental database}

As described in the previous section, the CPFEM model was calibrated using only a tensile test in the RD as well as the measured texture. In order to establish a more relevant one-to-one comparison, the phenomenological models were recalibrated using a reduced experimental database. The latter consists only of the stress-strain curves for the monotonic tensile tests at 0 , 45 and $90^{\circ}$ with respect to the rolling direction.

The identification procedure was simplified accordingly :

- isotropic hardening parameters and a reference yield stress were identified considering the three tensile tests

- yield function shape parameters of Bron\&Besson model retained the reference values $\left(a=b_{1}=b_{2}=2\right)$

- anisotropy parameters were identified on the considered database

Calibration of the models was conducted as previously, with the SiDoLo software, and the obtained parameter sets are given in Table 7 and Table 8. Then, the entire set of tests was simulated with this new set of parameters.

\begin{tabular}{ccccccc}
$F$ & $G$ & $N$ & $\sigma_{0}$ & $\sigma_{\text {sat }}$ & $C_{R}$ & $n$ \\
\hline 1.27 & 1.14 & 2.94 & 316 & 5780 & 0.11 & 0.55 \\
\hline
\end{tabular}

Table 7: Material parameters for the phenomenological model and Hill's 1948 yield function identified on the reduced database. $\sigma_{0}$ and $\sigma_{\text {sat }}$ are in MPa.

\begin{tabular}{cccccccc}
$c_{11}$ & $c_{12}$ & $c_{13}$ & $c_{14}$ & $\sigma_{0}$ & $\sigma_{\text {sat }}$ & $C_{R}$ & $n$ \\
\hline 1.11 & 0.97 & 0.95 & 1.01 & 316 & 5780. & 0.11 & 0.55 \\
\hline
\end{tabular}

Table 8: Material parameters for the phenomenological model and Bron\&Besson yield function identified on the reduced database. $\sigma_{0}$ and $\sigma_{\text {sat }}$ are in MPa. 


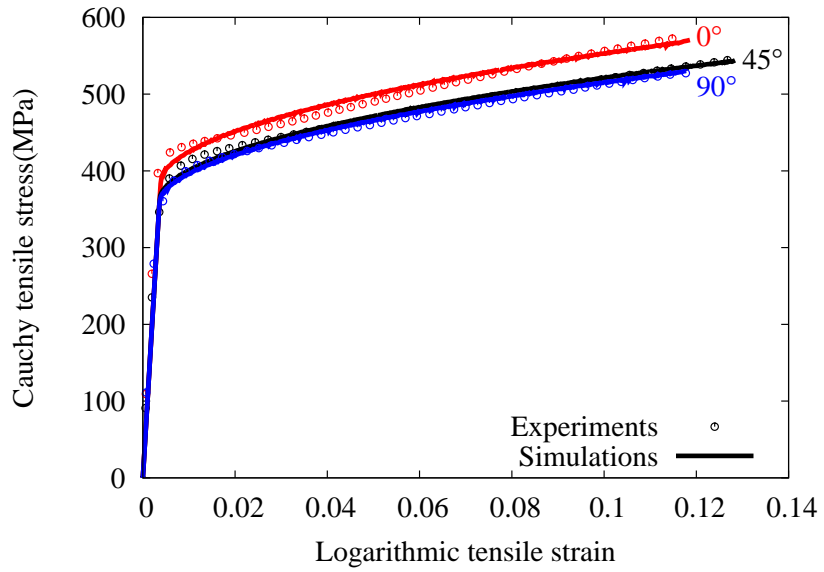

(a) Bron\&Besson (reduced database)

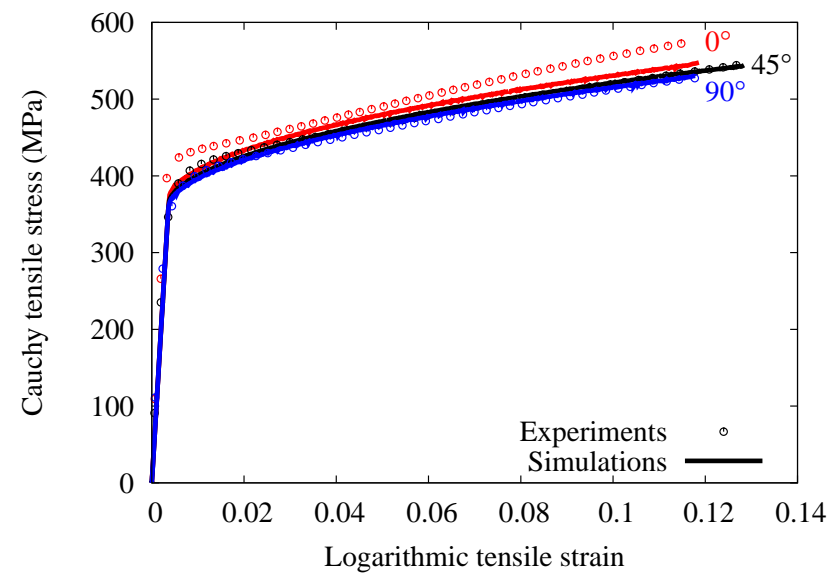

(b) Hill (reduced database)

Figure 18: Prediction of the tensile tests at $0^{\circ}, 45^{\circ}$ and $90^{\circ}$ with the phenomenological model based on the reduced database using the yield functions of a) Bron\&Besson and b) Hill's 1948. Symbols show the experimental values. 


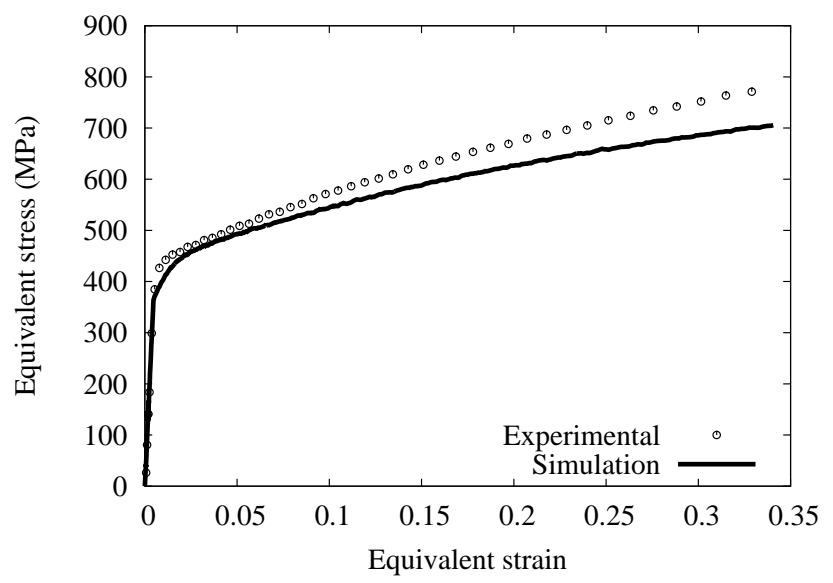

(a) Bron\&Besson (reduced database)

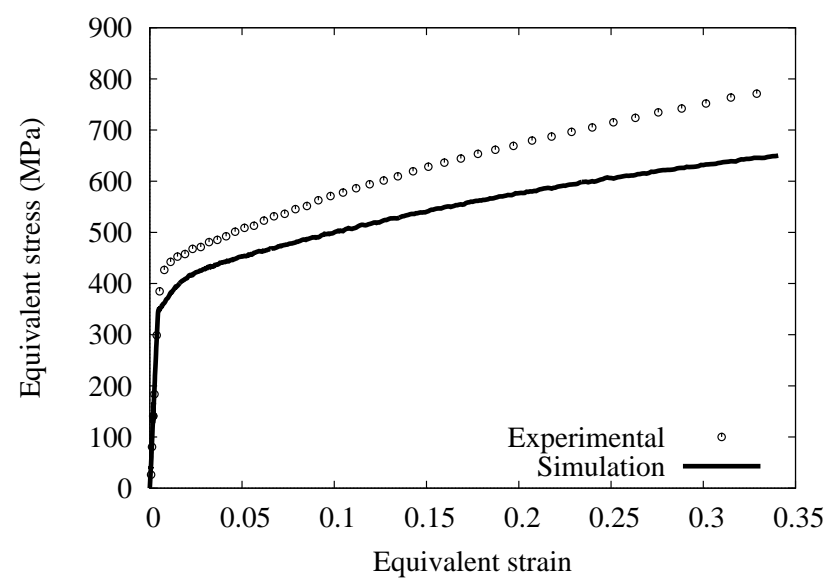

(b) Hill (reduced database)

Figure 19: Prediction of the hydraulic bulge tests with the phenomenological model based on the reduced database using the yield functions of a) Bron\&Besson and b) Hill's 1948. Symbols show the experimental values.

\subsection{Discussion}

When calibrated on the full experimental database, the Bron\&Besson model provided a good overall prediction of all the experiments and strain paths. Its eight anisotropy parameters enabled an excellent description of material anisotropy, both in flow stresses and plastic strain ratios. Let us recall that the parameter identification was performed to optimize simultaneously strain and stress anisotropy. Hill's 1948 model could not accurately capture both features. It couldn't account for the distinctive hardening slope at $0^{\circ}$ from the RD and only the plastic strain ratio at $45^{\circ}$ from the $\mathrm{RD}$ was well predicted. Nevertheless, it provided a description of equi-biaxial loading and shear tests nearly as good as the Bron\&Besson model. Stress anisotropy was still well predicted by Bron\&Besson model and failed using Hill's 1948 model. However, this time neither of the two models could predict any of the plastic strain ratios. Bron\&Besson model prediction for equi-biaxial loading was clearly better than Hill's 1948 model but still it considerably lacked accuracy for large strains. The monotonic shear test description was quite good for both models while kinematic hardening effects in reversed shear loading 


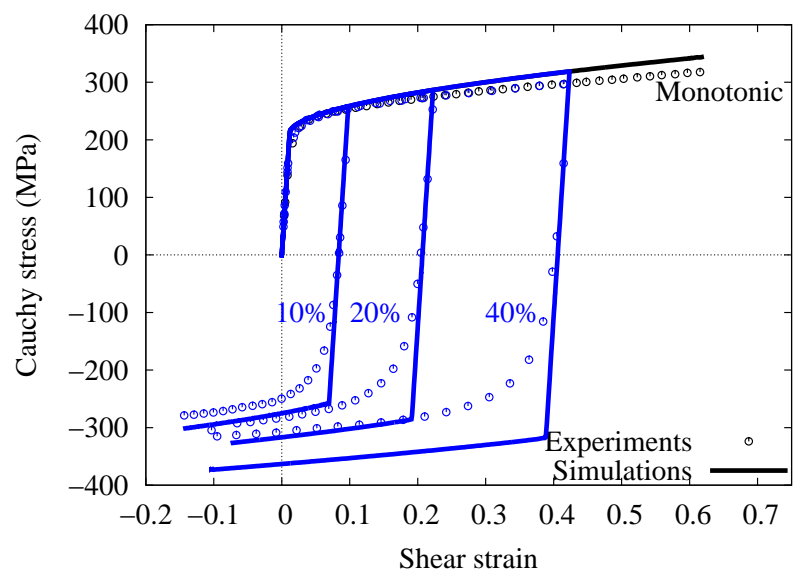

(a) Bron\&Besson (reduced database)

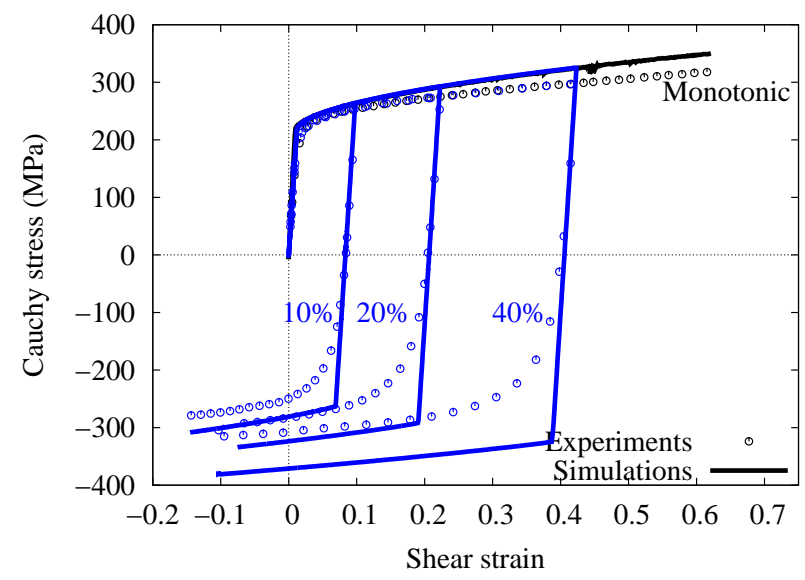

(b) Hill (reduced database)

Figure 20: Prediction of the monotonic and reversed shear tests with the phenomenological model based on the reduced database using the yield functions of a) Bron\&Besson and b) Hill's 1948. Symbols show the experimental values.

were not rendered as expected.

The CPFEM model, calibrated on a single tensile test in the RD and accounting for EBSD measured grain orientations, predicted remarkably well the stress-strain hardening curves. Thus, its predictions on stress anisotropy compare well with those of Bron\&Besson model. Regarding equi-biaxial loading as well as the monotonic and reversed shear tests description, phenomenological models calibrated on the reduced database were outperformed by the CPFEM model. The latter even performed equally well on equi-biaxial loading with the former calibrated on the full experimental database. However, CPFEM model monotonic and reversed shear tests predictions were not as accurate as full database calibrated phenomenological models ; especially for large pre-strained reversed shear loading, Bron\&Besson and Hill's 1948 models provide clearly more accurate predictions. Additionally, Fig. 22 shows that when it comes to strain anisotropy, the best description was clearly achieved by Bron\&Besson model calibrated on the full database. This time, simulations were made at every $5^{\circ}$ from the RD for the sake of completeness. The CPFEM model predictions were also in good agreement with experimen- 


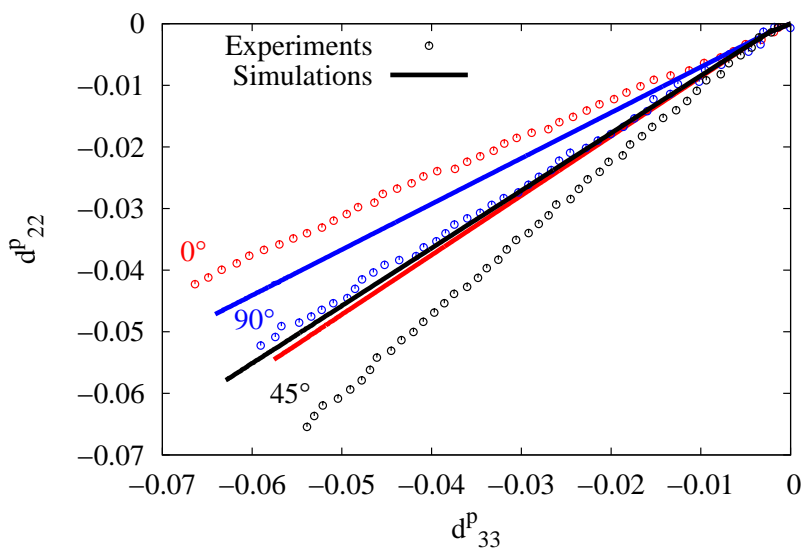

(a) Bron\&Besson (reduced database)

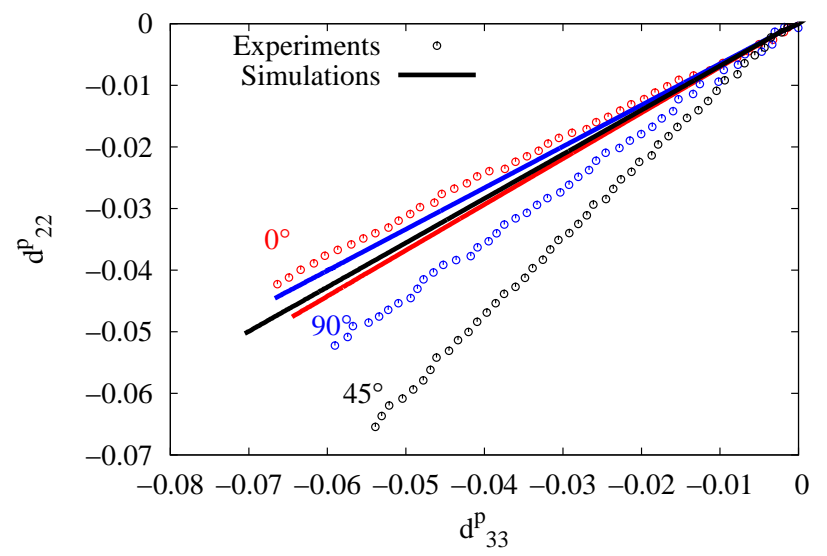

(b) Hill (reduced database)

Figure 21: Prediction of the plastic anisotropy ratios with the phenomenological model based on the reduced database using the yield functions of a) Bron\&Besson and b) Hill's 1948. Symbols show the experimental values.

tal data and this model gave the best description in the case of the reduced database.

Ultimately, the Bron\&Besson model calibrated on the extended database provided the best description with respect to the existing experiments, demonstrating the possibilities of advanced phenomenological material models. However, collecting such an amount of experimental data is time consuming and not always affordable. Indeed, usual material characterization for industrial purposes often consist of tensile tests such as the reduced database employed in this work. If one considers such a database, it is clear that the CPFEM model stands out as the best modeling choice in terms of accuracy and robustness. Furthermore, it must be stated that the CPFEM model employed in the present study was relatively basic and designed to embed the least possible parameters to fit. This was intented to obtain a model relying fundamentally on material microstructure and texture input in the present case. As a result, only 3 parameters had to be adjusted. Up to 28 and 19 parameters had to be calibrated on the full database respectively for Bron\&Besson model and Hill's 1948 model. The calibration procedure was far more com- 


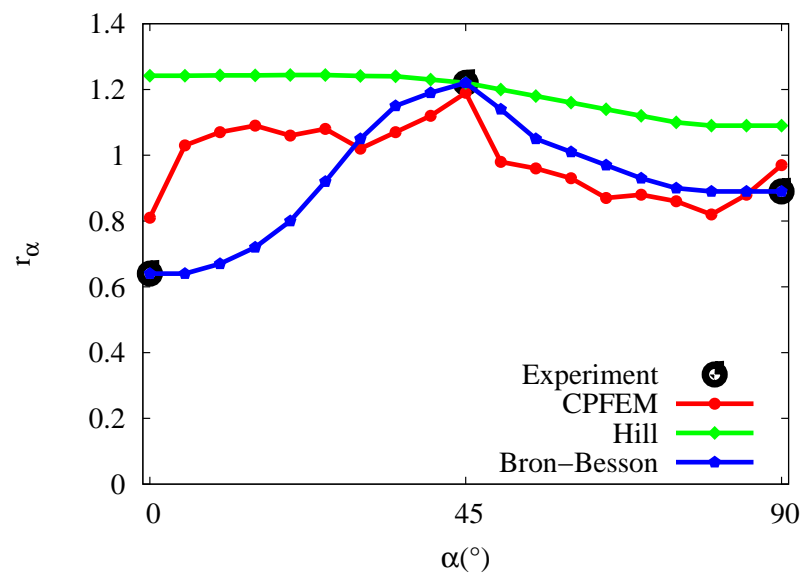

(a) Full database

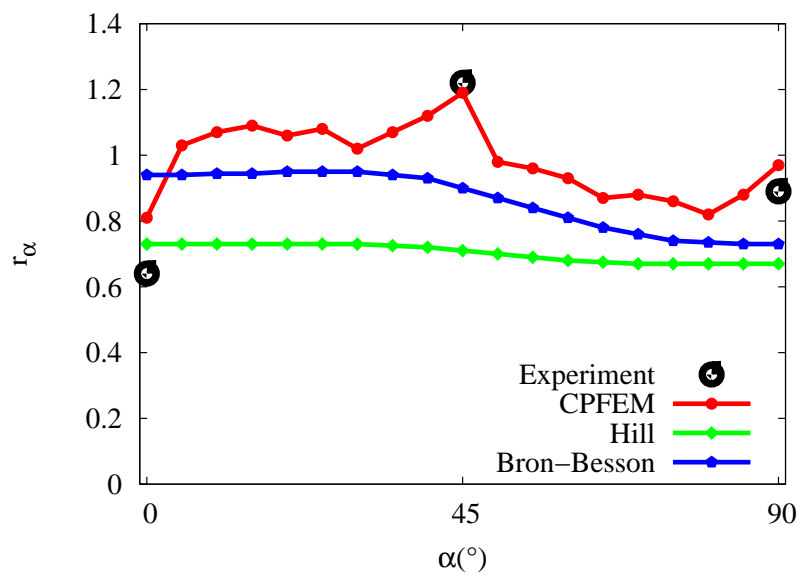

(b) Reduced database

Figure 22: Prediction of the plastic strain ratios at $0^{\circ}, 45^{\circ}$ and $90^{\circ}$ with the CPFEM model and the phenomenological models calibrated on the a) full experimental database and b) reduced experimental database.

587

plex for phenomenological models and required dedicated procedures and software. Additionally, it was demonstrated in the reduced database case that when confronted with strain paths that had not been accounted for in the calibration step, the phenomenological models could not provide good results. Consequently, the accuracy of phenomenological models calibrated on monotonic experiments alone (thus, involving only isotropic hardening) can be reasonably questioned whenever non-proportional strain paths may occur. In contrast, the CPFEM model calibrated on a single uniaxial tensile test proved capable of accurately predicting the mechanical response of a non annealed copper alloy under various strain paths, although its reverse loading predictions were not perfect. As it accounts for deformation mechanisms, the shapes and orientations of the grains, the CPFEM model has the potential to predict global material behavior.

\section{Conclusion}

State-of-the-art phenomenological models (Bron\&Besson, Hill's 1948) and a CPFEM classical model (Peirce-Asaro-Needleman type) were compared on 
their ability to describe the mechanical response of very thin copper alloy sheet metals under several strain paths. Theoretical and numerical implementation aspects as well as material calibration of material parameters of the models were presented. It can be summarized that :

- The phenomenological model based on the BB yield function provided the best results and accurately predicted all the mechanical tests on which it was calibrated

- Hill's 1948 could not perform well on the simultaneous description of stress and strain anisotropy

- both phenomenological models results were very sensitive to the scope of the experimental database considered for calibration ; their predictions quality was poor on a reduced database

- in contrast, a basic CPFEM model calibrated on a single tensile test provided an overall good description of all explored strain paths and strain anisotropy

- an initial stress inhomogeneity between grains in the CPFEM model improved the prediction of the reversed shear test (especially the Bauschinger effect) up to moderate pre-strains

Acknowledgements The French Agence Nationale de la Recherche is gratefully acknowledged for funding this work as well as Delta Composants for providing the sheet metals studied. The authors would also like to thank Anthony Jegat, Raphael Pesci, Célia Caer, Cong Han Pham, Cédric Bernard and Gilles Duchanois for their collaboration and fruitful discussions.

\section{References}

Amirkhizi, A. V., Nemat-Nasser, S., A framework for numerical integration of crystal elasto-plastic constitutive equations compatible with explicit finite element codes, International Journal of Plasticity 23 (2007) 1918-1937.

Armstrong, P. J., Frederick, C. O., A mathematical representation of the multiaxial Bauschinger effect, Central Electricity Generating Board [and] Berkeley Nuclear Laboratories, Research \& Development Dept., Berkeley, Gloucestershire, 1966. 
Balland, P., Déprés, C., Billard, R., Tabourot, L., Physically based kinematic hardening modelling of single crystal, American Institute of Physics Conference Series 1353 (2011) 91-96.

Banabic, D., Sheet metal forming processes constitutive modelling and numerical simulation, Springer, Berlin; London, 2010.

Barlat, F., Gracio, J. J., Lee, M.-G., Rauch, E. F., Vincze, G., An alternative to kinematic hardening in classical plasticity, International Journal of Plasticity 27 (2011) 1309-1327.

Beaudoin, A. J., Dawson, P. R., Mathur, K. K., Kocks, U. F., Korzekwa, D. A., Application of polycrystal plasticity to sheet forming, Computer Methods in Applied Mechanics and Engineering 117 (1994) 49-70.

Belkhabbaz, A., Bacroix, B., Brenner, R., Investigation of the elastoplastic behavior of FCC polycrytals using a FFT numerical scheme, Ro. J. Techn. Sci. - Appl. Mech. 60:1-2 10 (2015) 5-23.

Bron, F., Besson, J., A yield function for anisotropic materials. Application to aluminum alloys, International Journal of Plasticity 20 (2004) 937-963.

Cailletaud, G., Pilvin, P., Identification and Inverse Problems: A Modular Approach, ASME Applied Mechanics Division - Publications - AMD 168 (1993) 33.

Cailletaud, G., A micromechanical approach to inelastic behaviour of metals, International Journal of Plasticity 8 (1992) 55-73.

Chaboche, J. L., On some modifications of kinematic hardening to improve the description of ratchetting effects, International Journal of Plasticity 7 (1991) 661-678.

Diard, O., Leclercq, S., Rousselier, G., Cailletaud, G., Evaluation of finite element based analysis of 3D multicrystalline aggregates plasticity: Application to crystal plasticity model identification and the study of stress and strain fields near grain boundaries, International Journal of Plasticity 21 (2005) 691-722.

Dumoulin, S., Hopperstad, O., Berstad, T., Investigation of integration algorithms for rate-dependent crystal plasticity using explicit finite element codes, Computational Materials Science 46 (2009) 785-799. 
Dumoulin, S., Engler, O., Hopperstad, O. S., Lademo, O. G., Description of plastic anisotropy in AA6063-T6 using the crystal plasticity finite element method, Modelling and Simulation in Materials Science and Engineering 20 (2012) 055008.

Engel, U., Eckstein, R., Microforming - from basic research to its realization, Journal of Materials Processing Technology 125-126 (2002) 35-44.

Erieau, P., Rey, C., Modeling of deformation and rotation bands and of deformation induced grain boundaries in IF steel aggregate during large plane strain compression, International Journal of Plasticity 20 (2004) 1763-1788.

Franz, G., Abed-Meraim, F., Lorrain, J.-P., Ben Zineb, T., Lemoine, X., Berveiller, M., Ellipticity loss analysis for tangent moduli deduced from a large strain elastic-plastic self-consistent model, International Journal of Plasticity 25 (2009) 205-238.

Geißdörfer, S., Engel, U., Geiger, M., FE-simulation of microforming processes applying a mesoscopic model, International Journal of Machine Tools and Manufacture 46 (2006) 1222-1226.

Geiger, M., Kleiner, M., Eckstein, R., Tiesler, N., Engel, U., Microforming, CIRP Annals - Manufacturing Technology 50 (2001) 445-462.

Gitman, I. M., Askes, H., Sluys, L. J., Representative volume: Existence and size determination, Engineering Fracture Mechanics 74 (2007) 2518-2534.

Grujicic, M., Batchu, S., Crystal plasticity analysis of earing in deep-drawn OFHC copper cups, Journal of Materials Science 37 (2002) 753-764.

Guan, Y., Pourboghrat, F., Barlat, F., Finite element modeling of tube hydroforming of polycrystalline aluminum alloy extrusions, International Journal of Plasticity 22 (2006) 2366-2393.

Haddadi, H., Bouvier, S., Banu, M., Maier, C., Teodosiu, C., Towards an accurate description of the anisotropic behaviour of sheet metals under large plastic deformations: Modelling, numerical analysis and identification, International Journal of Plasticity 22 (2006) 2226-2271. 
Haddag, B., Balan, T., Abed-Meraim, F., Investigation of advanced strainpath dependent material models for sheet metal forming simulations, International Journal of Plasticity 23 (2007) 951-979.

Hibbitt, K. a. S., ABAQUS: Theory manual, Hibbitt, Karlsson \& Sorensen, Providence, R.I., 1992.

Hill, R., A theory of the yielding and plastic flow of anisotropic metals, Proceedings of the Royal Society of London A: Mathematical, Physical and Engineering Sciences 193 (1948) 281-297.

Kalidindi, S., Anand, L., An approximate procedure for predicting the evolution of crystallographic texture in bulk deformation processing of fcc metals, International Journal of Mechanical Sciences 34 (1992) 309-329.

Kanit, T., Forest, S., Galliet, I., Mounoury, V., Jeulin, D., Determination of the size of the representative volume element for random composites: statistical and numerical approach, International Journal of Solids and Structures 40 (2003) 3647-3679.

Karafillis, A. P., Boyce, M. C., A general anisotropic yield criterion using bounds and a transformation weighting tensor, Journal of the Mechanics and Physics of Solids 41 (1993) 1859-1886.

Khadyko, M., Dumoulin, S., Cailletaud, G., Hopperstad, O. S., Latent hardening and plastic anisotropy evolution in AA6060 aluminium alloy, International Journal of Plasticity (2015).

Khan, A. S., Liu, J., Yoon, J. W., Nambori, R., Strain rate effect of high purity aluminum single crystals: Experiments and simulations, International Journal of Plasticity 67 (2015) 39-52.

Kim, J.-B., Yoon, J. W., Necking behavior of AA 6022-T4 based on the crystal plasticity and damage models, International Journal of Plasticity 73 (2015) 3-23.

Kim, J. H., Kim, D., Barlat, F., Lee, M.-G., Crystal plasticity approach for predicting the Bauschinger effect in dual-phase steels, Materials Science and Engineering: A 539 (2012) 259-270. 
Kröner, E., Zur plastischen verformung des vielkristalls, Acta Metallurgica 9 (1961) 155-161.

Lebensohn, R. A., Tomé, C. N., A self-consistent anisotropic approach for the simulation of plastic deformation and texture development of polycrystals: Application to zirconium alloys, Acta Metallurgica et Materialia 41 (1993) 2611-2624.

Lee, M. G., Lim, H., Adams, B. L., Hirth, J. P., Wagoner, R. H., A dislocation density-based single crystal constitutive equation, International Journal of Plasticity 26 (2010) 925-938.

Li, H., Yang, H., Sun, Z., A robust integration algorithm for implementing rate dependent crystal plasticity into explicit finite element method, International Journal of Plasticity 24 (2008) 267-288.

Li, Y., Aubin, V., Rey, C., Bompard, P., Polycrystalline numerical simulation of variable amplitude loading effects on cyclic plasticity and microcrack initiation in austenitic steel 304l, International Journal of Fatigue 42 (2012) 71-81.

Li, L., Shen, L., Proust, G., A texture-based representative volume element crystal plasticity model for predicting Bauschinger effect during cyclic loading, Materials Science and Engineering: A 608 (2014) 174-183.

Lin, B., Zhao, L. G., Tong, J., Christ, H. J., Crystal plasticity modeling of cyclic deformation for a polycrystalline nickel-based superalloy at high temperature, Materials Science and Engineering: A 527 (2010) 3581-3587.

Needleman, A., Asaro, R., Lemonds, J., Peirce, D., Finite element analysis of crystalline solids, Computer Methods in Applied Mechanics and Engineering 52 (1985) 689-708.

Peirce, D., Asaro, R., Needleman, A., An analysis of nonuniform and localized deformation in ductile single crystals, Acta Metallurgica 30 (1982) $1087-1119$.

Peirce, D., Asaro, R. J., Needleman, A., Material rate dependence and localized deformation in crystalline solids, Acta Metallurgica 31 (1983) 1951-1976. 
Peng, L., Liu, F., Ni, J., Lai, X., Size effects in thin sheet metal forming and its elastic-plastic constitutive model, Materials \& Design 28 (2007) $1731-1736$.

Pham, C.-H., Thuillier, S., Manach, P.-Y., Mechanical Properties Involved in the Micro-forming of Ultra-thin Stainless Steel Sheets, Metallurgical and Materials Transactions A 46 (2015) 3502-3515.

Quey, R., Dawson, P. R., Barbe, F., Large-scale 3d random polycrystals for the finite element method: Generation, meshing and remeshing, Computer Methods in Applied Mechanics and Engineering 200 (2011) 1729-1745.

Raphanel, J., Ravichandran, G., Leroy, Y., Three-dimensional ratedependent crystal plasticity based on Runge-Kutta algorithms for update and consistent linearization, International Journal of Solids and Structures 41 (2004) 5995-6021.

Rice, J., Inelastic constitutive relations for solids: An internal-variable theory and its application to metal plasticity, Journal of the Mechanics and Physics of Solids 19 (1971) 433-455.

Roters, F., Eisenlohr, P., Hantcherli, L., Tjahjanto, D., Bieler, T., Raabe, D., Overview of constitutive laws, kinematics, homogenization and multiscale methods in crystal plasticity finite-element modeling: Theory, experiments, applications, Acta Materialia 58 (2010) 1152-1211.

Rousselier, G., Barlat, F., Yoon, J., A novel approach for anisotropic hardening modeling. Part I: Theory and its application to finite element analysis of deep drawing, International Journal of Plasticity 25 (2009) 2383-2409.

Schmid, E., Boas, W., Rawlins, F. I. G., Kristallplastizität, The Journal of Physical Chemistry 39 (1934) 1248-1248.

Segurado, J., Lebensohn, R. A., LLorca, J., Tomé, C. N., Multiscale modeling of plasticity based on embedding the viscoplastic self-consistent formulation in implicit finite elements, International Journal of Plasticity 28 (2012) 124-140.

Sidoroff, F., Incremental constitutive equation for large strain elasto plasticity, International Journal of Engineering Science 20 (1982) 19-26. 
Tabourot, L., Loi de comportement élastoviscoplastique du monocristal en grandes transformations, Ph.D. thesis, Institut National Polytechnique de Grenoble., 1992.

Tabourot, L., Vers une vision unifiée de la plasticité cristalline, Habilitation à Diriger des Recherches, Université de Savoie, 2001.

Tarasiuk, J., Wierzbanowski, K., Bacroix, B., Texture decomposition into Gauss-shaped functions: classical and genetic algorithm methods, Computational Materials Science 29 (2004) 179-186.

Taylor, G. I., Elam, C. F., Bakerian Lecture. The Distortion of an Aluminium Crystal during a Tensile Test, Proceedings of the Royal Society of London. Series A, Containing Papers of a Mathematical and Physical Character 102 (1923) 643-667.

Taylor, G. I., Plastic Strain in Metals, Journal of the Institute of Metals 62 (1938) 307-324.

Thuillier, S., Manach, P. Y., Comparison of the work-hardening of metallic sheets using tensile and shear strain paths, International Journal of Plasticity 25 (2009) 733-751.

Van Houtte, P., Li, S., Seefeldt, M., Delannay, L., Deformation texture prediction: from the Taylor model to the advanced Lamel model, International Journal of Plasticity 21 (2005) 589-624.

Verma, R. K., Kumar, A., Manikandan, G., Kuwabara, T., Modelling anisotropic hardening of an ultra low carbon high strength steel using crystal plasticity, Materials Science and Engineering: A 559 (2013) 359363.

Wang, S., Zhuang, W., Balint, D., Lin, J., A virtual crystal plasticity simulation tool for micro-forming, Procedia Engineering 1 (2009) 75-78.

Yoshida, F., Uemori, T., A model of large-strain cyclic plasticity and its application to springback simulation, International Journal of Mechanical Sciences 45 (2003) 1687-1702.

Yoshida, F., Hamasaki, H., Uemori, T., Modeling of anisotropic hardening of sheet metals including description of the Bauschinger effect, International Journal of Plasticity 75 (2015) 170-188. 
Zamiri, A., Pourboghrat, F., Barlat, F., An effective computational algorithm for rate-independent crystal plasticity based on a single crystal yield surface with an application to tube hydroforming, International Journal of Plasticity 23 (2007) 1126-1147.

Zang, S., Thuillier, S., Le Port, A., Manach, P. Y., Prediction of anisotropy and hardening for metallic sheets in tension, simple shear and biaxial tension, International Journal of Mechanical Sciences (2011) 338-347.

Zhang, H., Dong, X., Wang, Q., Zeng, Z., An effective semi-implicit integration scheme for rate dependent crystal plasticity using explicit finite element codes, Computational Materials Science 54 (2012) 208-218.

Zhang, K., Holmedal, B., Dumoulin, S., Hopperstad, O. S., An explicit integration scheme for hypo-elastic viscoplastic crystal plasticity, Transactions of Nonferrous Metals Society of China 24 (2014) 2401-2407.

Zhang, K., Holmedal, B., Hopperstad, O. S., Dumoulin, S., Gawad, J., Van Bael, A., Van Houtte, P., Multi-level modelling of mechanical anisotropy of commercial pure aluminium plate: Crystal plasticity models, advanced yield functions and parameter identification, International Journal of Plasticity 66 (2015) 3-30. 